\title{
WestVirginiaUniversity
}

THE RESEARCH REPOSITORY @ WVU

Graduate Theses, Dissertations, and Problem Reports

2018

\section{Dynamic Modeling and Advanced Control of a Refinery Hydrocracker Process}

\author{
Christian Ayafor
}

Follow this and additional works at: https://researchrepository.wvu.edu/etd

\section{Recommended Citation}

Ayafor, Christian, "Dynamic Modeling and Advanced Control of a Refinery Hydrocracker Process" (2018). Graduate Theses, Dissertations, and Problem Reports. 7157.

https://researchrepository.wvu.edu/etd/7157

This Thesis is protected by copyright and/or related rights. It has been brought to you by the The Research Repository @ WVU with permission from the rights-holder(s). You are free to use this Thesis in any way that is permitted by the copyright and related rights legislation that applies to your use. For other uses you must obtain permission from the rights-holder(s) directly, unless additional rights are indicated by a Creative Commons license in the record and/ or on the work itself. This Thesis has been accepted for inclusion in WVU Graduate Theses, Dissertations, and Problem Reports collection by an authorized administrator of The Research Repository @ WVU. For more information, please contact researchrepository@mail.wvu.edu. 


\title{
Dynamic Modeling and Advanced Control of a Refinery Hydrocracker Process
}

\author{
Christian Ayafor \\ Thesis submitted to the \\ Benjamin M. Statler College of Engineering and Mineral Resources \\ at West Virginia University \\ in partial fulfillment of the requirements \\ for the degree of \\ Master of Science \\ in
}

Chemical Engineering

Debangsu Bhattacharyya, Ph.D., Committee Chairperson John Hu, Ph.D.

Fernando V. Lima, Ph.D.

Department of Chemical and Biomedical Engineering

Morgantown, West Virginia

2018

Keywords: Hydrocracker, continuous kinetic lumping, Quadratic dynamic matrix control

Copyright 2018 Christian Ayafor 


\title{
ABSTRACT \\ Dynamic Modeling and Advanced Control of a Refinery Hydrocracker Process
}

\author{
Christian Ayafor
}

Development of a dynamic non-isothermal hydrocracker model that can estimate temperatures and concentration profile along the reactor is undertaken in this work. With reaction kinetics being critical to modeling and simulation of a hydrocracking reactor, the complex chemistry of hydrocarbons is represented by a continuous lumping approach. The true boiling points of the mixture are used as characterization parameters.

A parameter estimation framework is developed for estimating the key kinetic parameters for the continuous kinetic lumping approach. Experimental data for Maya crude oil obtained before and after cracking through a bench-scale hydrocracking reactor are used to obtain parameters for the continuous kinetic lumping technique.

The model is used to study the impact of a number of key variables. Finally a model-based controller is developed for controlling the weight fractions of gasoline, and/or kerosene, and/or diesel in the final product. A linear model is identified and used in the model-based control. Both single input single output (SISO) and multiple input multiple output (MIMO) controllers are developed. Servo control and disturbance rejection characteristics of the controllers are studied. 


\section{DEDICATION}

To my late mother, Mrs. Ngongpa Esther Pikieh,

for her encouragements and relentless sacrifices 


\section{ACKNOWLEDGEMENTS}

Undertaking a Master of science in Chemical Engineering at the Benjamin M. Statler College of Engineering and Mineral Resources of West Virginia University, has granted me the opportunity to meet and interact with great engineers and researchers and have greatly contributed in improving my research, scientific and engineering skills. Since I joined this program at WVU in august 2016, I have had memorable experiences and developed a support network of professors and students in whom I can rely on as I move on in facing what the future reserves for me.

My research advisor, Dr. Debangsu Bhattacharyya, has been an exemplary guide, and has relentlessly paved the way for me to understanding scientific and engineering concepts, as well as providing long lasting solutions to difficulties faced in research and development. I will eternally be grateful to him for his patience, his mentorship and for accepting me into his research team.

Also, I will like to thank my Advisory and Examining Committee members, Dr. Fernando V. Lima and Dr. John Hu, for their availability, advice and support throughout my research. Special thanks to them for the constructive comments they made towards my research proposal, and for making out time to make sure that my defense went on well.

The beginnings at WVU were quite hectic, but thanks to several professors whom I was fortunate to meet, the rest of my stay became adorable. I would like to acknowledge the professors that made chemical engineering fun for me. Special thanks again to Dr. Debangsu Bhattacharyya, for adequately advising me on the courses to undertake to become a chemical engineer and researcher, and for the Optimization course that greatly helped me throughout my research. Thanks to Dr. Jeremy Hardinger, for properly introducing me into Thermodynamics and separation processes applied to chemical processes. Dr. Yong Yang, for simplifying transport analysis and making the concepts easy to grasp. Thanks to Prof. Charter Stinespring, who used theory to make me clearly visualize the practical applications of thermodynamics in engineering. Thanks to Dr. 
John $\mathrm{Hu}$, who designed a course that permitted me to apply my chemical engineering concepts into petroleum and refinery processes. Special thanks to Dr. Lima for his advance process control course, which gave me an insight into process controls and was very determinant in my research. I would also like to thank Dr. Hanjing Tian for his great knowledge in chemical reaction engineering. Special thanks to Prof. Rakesh Gupta, for complementing my knowledge in Transport phenomena and for making the class easy. Thanks to Dr. Ali Feliachi, for the linear and optimal control courses, and to Prof. Natalia Schmid, for a proper introduction into stochastic systems theory. I will end by thanking all the staff and students of the chemical and biomedical engineering department that made all our Friday mornings a forum for intellectual and scientific exchange.

I want to acknowledge all the members of the Advanced Process and Energy Systems Engineering Group, who were a great source of inspiration and exchange throughout my studies and research at WVU. Special thanks to: Qiao, Joshua, Yuan, Anderson, Dustin, Jacob, Samson, Chirag, Anca, Yifan, Paul, Ryan, Goutham, Pushpitha, Katie, Elijah, Parikshit.

I will eternally be grateful to my family, for their sacrifices throughout my studies. I am grateful for the unconditional support illustrated on my behalf by Tansah Asonyu Vanessa, MD, from the beginning of my program at WVU, throughout my studies and research and above all for her support in helping me overcome the indescribable pain of my mother's passing away.

Special thanks to Taiwo Ajayi, Ph.D., Selorme Agbleze and Akondi Rawlings who have always been there to listen and to provide necessary support during my stay at WVU.

I will like to appreciate the support from the Fulbright program, without which undertaking studies at WVU won't have been possible.

Finally, I will like to thank God Almighty, for his protection and guidance over my life. 


\section{TABLE OF CONTENTS}

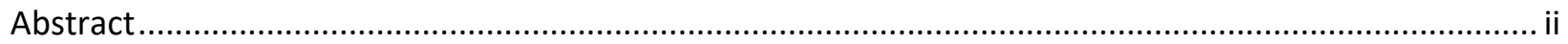

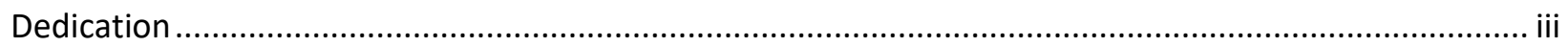

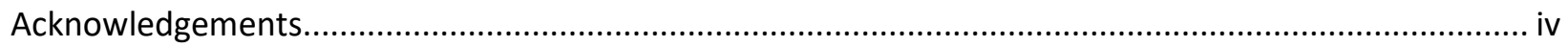

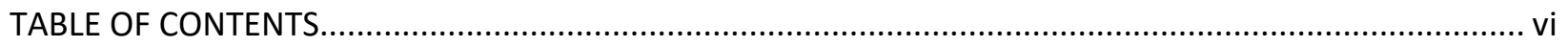

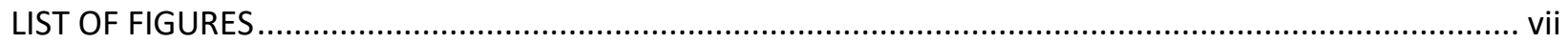

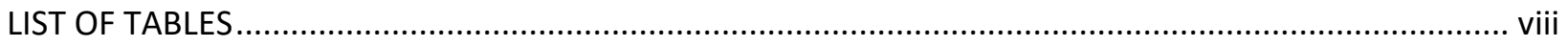

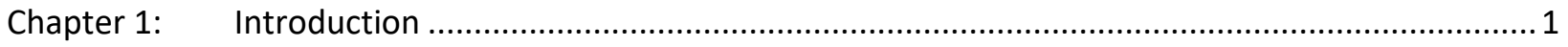

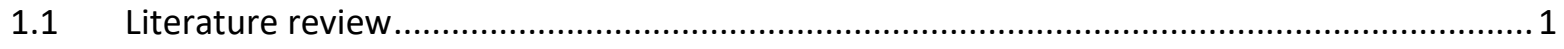

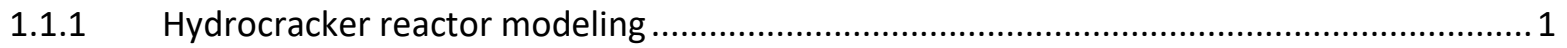

1.1.2 Advanced Process Control ..................................................................................... 2

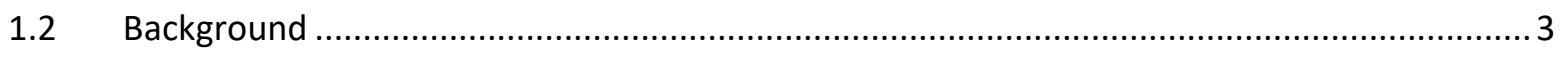

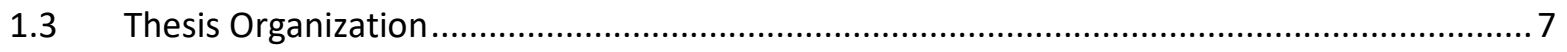

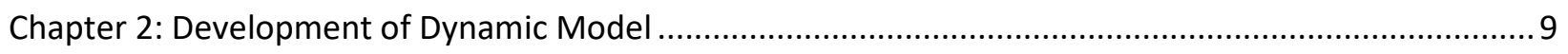

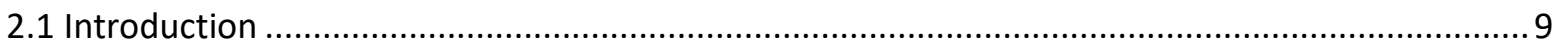

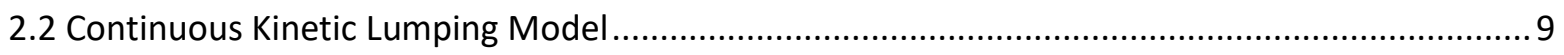

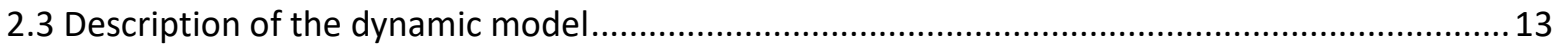

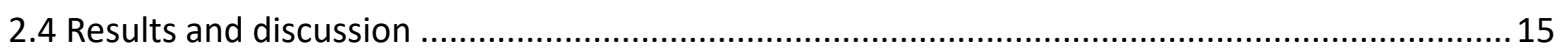

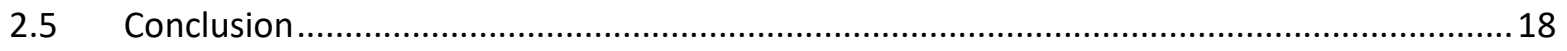

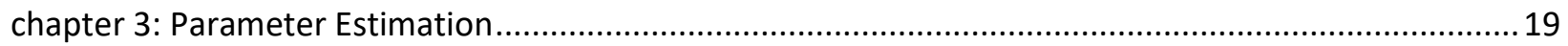

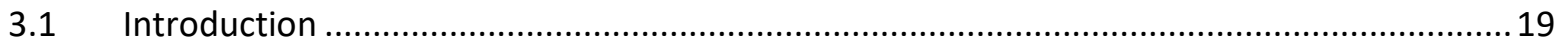

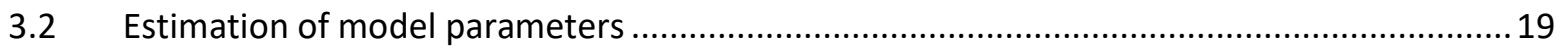

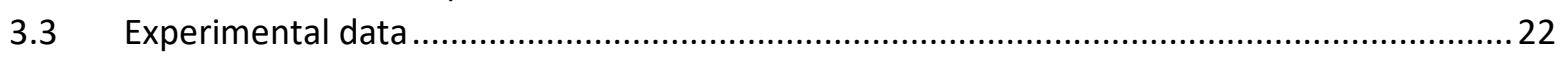

3.4 Separation of Experimental data into lumps ..................................................................... 22

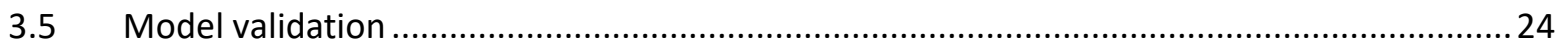

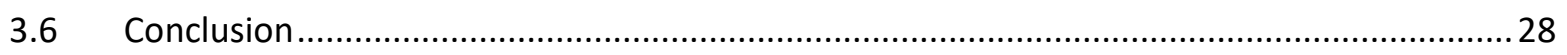

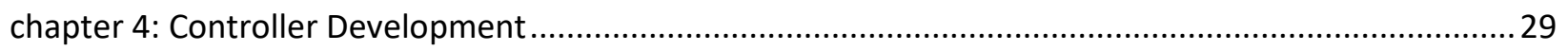

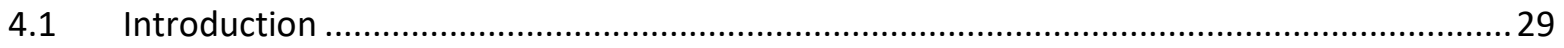

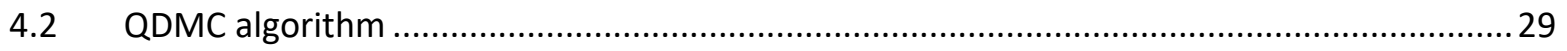

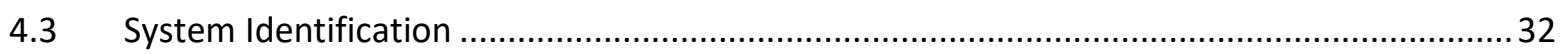

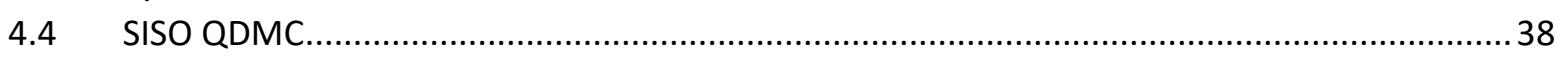

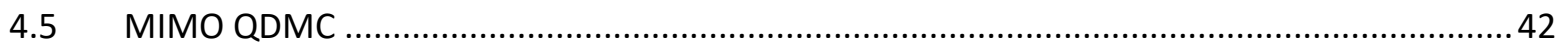

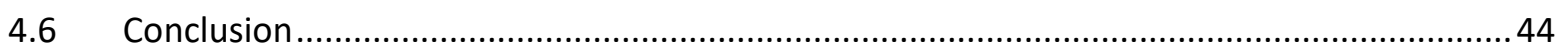

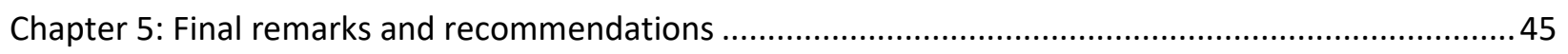

APPENDIX A: composition of feed and hydrocracked products with a FBP of $700{ }^{\circ} \mathrm{C} \ldots \ldots \ldots \ldots \ldots \ldots \ldots \ldots \ldots . . . . . . . . . . . . . . .46$

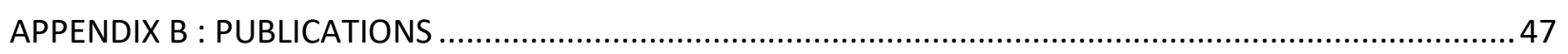

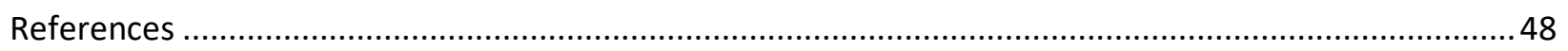




\section{LIST OF FIGURES}

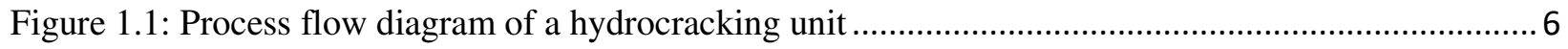

Figure 2.1: Algorithm for the dynamic mass and energy balance using continuous kinetic lumping ........ 14

Figure 2.2: Cumulative dimensionless continuous concentration $(\mathrm{c}(\mathrm{t}, \tau, \mathrm{k}))$ for the ten nodes at $400{ }^{\circ} \mathrm{C}, 8.3$

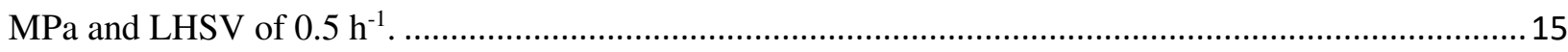

Figure 2.3: Cumulative weight fractions at different input Temperatures at $8.3 \mathrm{MPa}$ and LHSV of $0.5 \mathrm{~h}^{-1}$.

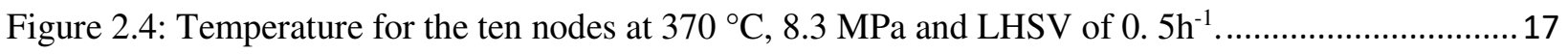

Figure 2.5: Temperature for the ten nodes at $400{ }^{\circ} \mathrm{C}, 8.3 \mathrm{MPa}$ and LHSV of $0.5 \mathrm{~h}^{-1} \ldots \ldots \ldots \ldots \ldots \ldots \ldots \ldots \ldots . . . . . . . . . . . . .17$

Figure 3.1: Algorithm for parameter estimation for the continuous kinetic lumping model ......................21

Figure 3.2: Comparison of experimental data versus model results for the feed $\left(\mathrm{T}=400{ }^{\circ} \mathrm{C}, \mathrm{P}=8.3 \mathrm{MPa}\right.$,

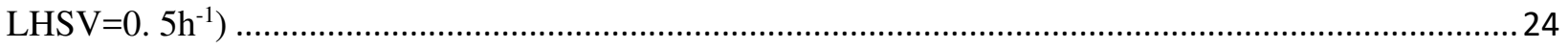

Figure 3.3: Comparison of experimental data versus model results for the product $\left(\mathrm{T}=400{ }^{\circ} \mathrm{C}, \mathrm{P}=8.3 \mathrm{MPa}\right.$,

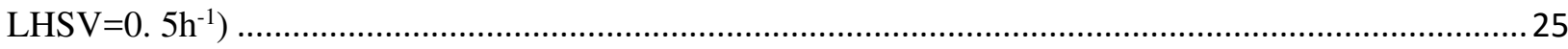

Figure 3.4: Comparison between the model results and experimental data for the cumulative weights of

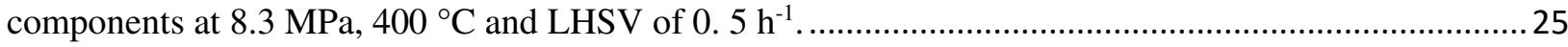

Figures 3.5: Dependence of the continuous kinetic model parameters with temperature at $8.3 \mathrm{MPa}$ and

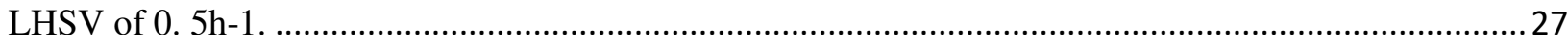

Figure 4.1: Illustration of step response parameter identification........................................................ 29

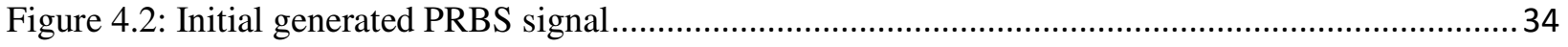

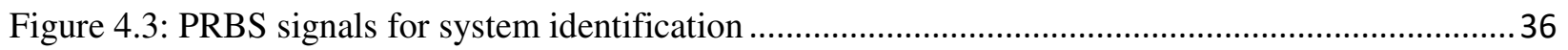

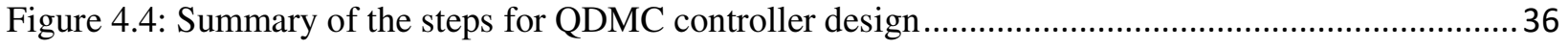

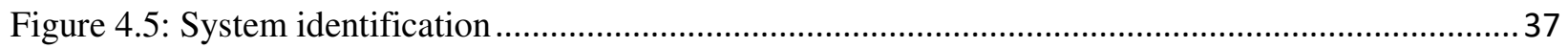

Figure 4.6: Input and output response of QDMC for gasoline weight fraction control ............................. 39

Figure 4.7: Input and output response of QDMC for kerosene weight fraction control ............................. 39

Figure 4.8: Input and output response of QDMC for diesel weight fraction control................................ 40

Figure 4.9: Disturbance rejection characteristics of QDMC for gasoline control .................................... 41

Figure 4.10: Disturbance rejection characteristics of QDMC for kerosene control.................................. 41

Figure 4.11: Disturbance rejection characteristics of QDMC for diesel control ......................................42

Figure 4.12: Input and output response of MIMO QDMC for gasoline and kerosene weight control ....... 43 


\section{LIST OF TABLES}

Table 1: Lumps of feed and hydrocracked products with a FBP of $700{ }^{\circ} \mathrm{C}$ .23 


\section{CHAPTER 1: INTRODUCTION}

The growing demand of valuable middle distillates and the increase in production of sour and heavy crude oils has prompted refineries to use hydrocracking units to play the central role for the conversion of the middle and bottom distillates from the crudes into the desired products.

A non-isothermal dynamic model of the hydrocracker that can predict the product composition can be very valuable for the optimal control of these plants so that the plant profit can be maximized without violating the product quality constraints.

\subsection{Literature review}

\subsubsection{Hydrocracker reactor modeling}

Several models for the hydrocracking of heavy oil are available in the literature. Ancheyta et al. [1] have grouped these kinetic models into four major categories. The first category is the simplest and considers only one lumped product. An example of work in this category is that of Qader and Hill [2]. The reaction rate is considered to be first order in terms of the feed concentration. The second category proposed by Callejas and Martinez [3] considers three-lump species using first-order kinetics. Linear regression is used for estimating the kinetic parameters for models under categories 1 and 2. It was reported that the parameter estimation problem becomes increasingly difficult as the number of components increase. The third category of models is based on discrete lumping. Stangeland [4] developed such a kinetic model that used correlations based on boiling points. The model requires parameters for given types of feed (naphthenic or paraffinic) and catalytic process type (random or selective). The fourth category is based on continuous mixtures and uses initial boiling point temperatures as characterization parameters. One such model is presented by Laxminarasimhan et al. [5]. This model requires five parameters to be estimated.

After studying the state-of-the-art of mild hydrocracking processes, including reaction 
networks and kinetics, Chaudhuri et al. [6] suggested that pseudo-components be considered in modeling the reaction kinetics due to the complexity of industrial feedstocks.

Elizalde et al. [7] have applied the continuous kinetic lumping approach to design a hydrocracking reactor capable of predicting both the mass fraction and the temperature of the products. The authors found that the constant heat capacity assumption for the whole mixture is reasonable since it only results in a small difference in the temperature at the middle of the reactor if the heat capacity is considered to be different for each lump.

Sildir et al. [8] modeled a dynamic non-isothermal hydrocracker reactor using the continuous lumping method. Data from an industrial setup was used. Predicted product yields under steady-state and dynamic operating conditions and reactor temperature matched plant data. Aydin et al. [9] modeled a dynamic industrial diesel hydroprocessing plant using the continuous kinetic lumping method. The models consisted of a hydrodesulfurization and a hydrocracker reactor and were validated using plant data. Predicted reactor bed temperatures, sulfur removal, and diesel production under steady-state and dynamic conditions were in good agreement with the plant data.

The continuous kinetic lumping approach has produced results that are comparable to the plant data. Therefore, the kinetic model developed in this work will be based on the continuous lumping approached. Parameters are estimated using the methodology provided by Elizalde and Ancheyta [10].

\subsubsection{Advanced Process Control}

Model Predictive Control (MPC) was developed in the 1970s since performance of conventional single-loop controllers were unsatisfactory for the increasingly stringent performance requirements [11]. The MPC has evolved over the decades with the use of different algorithms. Cutler and Ramaker [12] successfully implemented Dynamic Matrix Control (DMC) on 
petrochemical processes. Garcia and Morari [13] developed Internal Model Control algorithm. Clarke et al. [14-15] designed a predictive algorithm which was suitable for the adaptive control of processes with varying parameters, dead-time and model order. Cutler and Hawkins [16] used the DMC on a hydrocracker process to reduce energy consumption. Rawlings and Muske [17] developed an infinite horizon controller for both stable and unstable linear plants, that allowed incorporation of input and state constraints in a receding horizon feedback strategy. Mayne et al. [18] devised a control algorithm in which the current control action was calculated by solving at each sampling instant a finite horizon open-loop optimal control problem; the algorithm used the current state of the plant as the initial state in order to predict the control move and the output. Qin \& Badgwell [19] have provided a review of the linear and non-linear MPC models especially from the perspective of their industrial implementation. General MPC control algorithms were discussed by the authors along with the methods developed by vendors in view of the practical implementation of these algorithms.

The past decade has seen a rise in the design of the hydrocracker reactor using the continuous kinetic lumping approach, but MPC algorithms have not been applied to the hydrocracker reactor modeled by using this continuous kinetic lumping approach. This work will consist of using the DMC to control a dynamic non-isothermal hydrocracker reactor designed following the continuous kinetic lumping approach.

\subsection{Background}

Hydrocracking is an important petrochemical process involving complex reactions that result in the conversion of higher boiling petroleum fractions into lower boiling petroleum fractions like gasoline, naphtha, kerosene, and diesel oil. This refinery process is vital, since it can process a wide variety of petroleum cuts to produce an array of light products that are low in 
impurities and sulfur.

Refineries mainly use fixed trickle-bed reactors (TBR) and the ebullated bed reactors (EBR) in hydrocracking units. In both cases, three phases are present during the reactions. Hydrogen and other gases are in the gas phase; the liquid phase comprises the liquid hydrocarbons while the solid phase comprises the catalyst. Hydrocracking is carried out in the presence of hydrogen at high temperatures $\left(260-495^{\circ} \mathrm{C}\right)$ and pressures (35-200 bar). The main reactions are cracking and hydrogenation and are supported by bifunctional catalysts such as bimetallic compounds (e.g. NiMo) on an acidic support (e.g. silica-alumina). The acidic site facilitates cracking while the metallic site facilitates the hydrogenation reactions. Although cracking reaction itself is endothermic, the overall hydrocracking process is exothermic since hydrogenation is highly exothermic [8].

As shown on Figure 1.1, a hydrocracking unit is generally made-up of two sets of reactors. The first stage (R1) is the hydrotreater that essentially converts nitrogen and sulfur compounds into ammonia and hydrogen sulfide, respectively. Also, olefins and aromatics present in the feed are hydrogenated. The feed is preheated by the feed/effluent exchanger E1. The furnace F1 heatsup hydrogen to the desired input temperature to the first stage. The product from R1 is mixed-up with recycle residue from the bottom of the distillation column (C1) and with hydrogen from the second furnace (F2) before it is injected into the second stage (R2). The hydrogen injection at R2 permits to cool down the feed being injected into the reactor and also provides the excess hydrogen that will be needed for the hydrocracking reactions. At the outlet of R2, exchangers E2 and E3 are used to cool down the feed before it passes through an air-cooler E4. The product is then injected into a high-pressure (HP) separator where sour water is removed and the separated recycle gas is re-injected into the process. The rest of the petroleum from the HP separator is injected to the low- 
pressure (LP) separator where off gas is collected before the petroleum is injected into C1 for separation into the different products. Reactions such as hydrogenation/dehydrogenation, beta scission, and isomerization occur in the second stage of the hydrocracking unit.

This research is focused on the design and control of this second stage of the hydrocracking unit, denoted as R2 here, that will be used in the MATLAB simulation software, in order to predict the composition of the products and temperatures under given operating conditions of the reactor. The effects of the change in the temperature of the feed on the composition of the products at a given liquid hourly space velocity (LHSV) and pressure are investigated. The steady state, isothermal model is used in MATLAB to estimate the parameters in the continuous kinetic lumping model. Furthermore, a validated reduced model is developed to be used in the advanced process control (APC) design and deployment. 


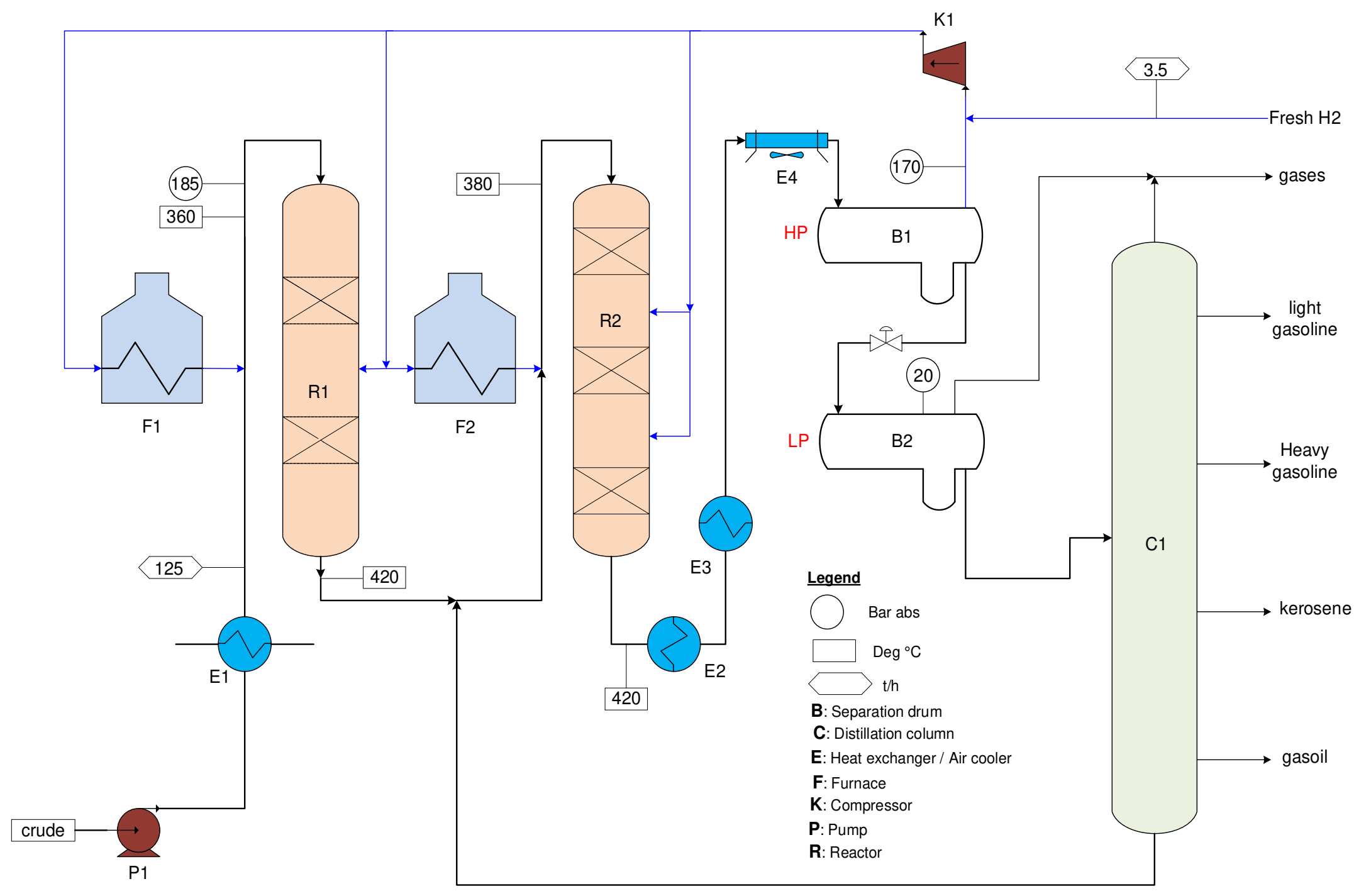

Figure 1.1: Process flow diagram of a hydrocracking unit 


\subsection{Thesis Organization}

This work is comprised of three distinct tasks: model development, parameter estimation, and development of the APC strategy. The contributions of this work for these tasks are described below.

\subsubsection{Modeling Contribution}

In the existing literature, dynamic hydrocracker models that use continuous lumping methods are very few. In this work, a detailed dynamic model is developed. The model is nonisothermal and considers spatial and temporal variation of the species through the reactor. Due to highly endothermic hydrocracking reactions, a rigorous energy balance model is considered in this work. As the product cracks and get hydrogenated through the reactor, its thermal properties change considerably; this aspect has been modeled.

\subsubsection{Parameter Estimation Contribution}

Model parameters are optimally estimated by using the experimental data. In this work, Aspen Plus is used for obtaining the different lumps for the experimental feed and products. As a result, the dimensionless temperature $(\theta)$ (this parameter plays a key role as explained later) for the different cumulative weights is no longer interpolated as is typically done in the existing literature. Various strategies are developed to reduce the computational time for this complex parameter estimation problem.

\subsubsection{Controller Development Contribution}

DMC is developed in this work for controlling the hydrocracker outlet composition. Both servo control and disturbance rejection performances are studied for the single input single output (SISO) model. A multiple input multiple output (MIMO) model is also developed in order to control two products at the output of the reactor simultaneously. System identification is performed 
using the data generated by a pseudo random binary signal (PRBS) [20-21] finally generating a state-space model of the system [22-23]. 


\section{CHAPTER 2: DEVELOPMENT OF DYNAMIC MODEL}

\subsection{Introduction}

This chapter is focused on the development of the dynamic non-isothermal hydrocracker reactor. The method used for the development of this reactor is the continuous kinetic lumping technique, which will be visited in detail. In the past, different techniques were used to model hydrocracker reactors, but the continuous kinetic lumping technique has proven to be the most effective and has seen a surge in its use by researchers in the past decade. The implementation of the set of equations developed in this chapter for this technique is done in the Matlab software.

\subsection{Continuous Kinetic Lumping Model}

The following assumptions are made when modeling the hydrocracker reactor using the continuous kinetic lumping model [7] [24]:

Radial and axial dispersion are neglected assuming that the reactor behaves as an ideal plug flow,

Due to the excess amount of hydrogen the reactions are considered to be first order $\left(k C_{A}\right)$,

$>$ Steady-state operation and isothermal conditions are assumed while validating with the experimental data,

$>$ Reactivity of species is related to its boiling temperature so that the reactivity increases with TBP and vice versa (feedstock considered to be long carbon chains).

\subsubsection{Mass Balance}

The following integro-differential equation is considered for the mass balance [10] [24] :

$$
\frac{\partial C(k, \tau, t)}{\partial t}=-\frac{\partial C(k, \tau, t)}{\partial \tau}-k C(k, \tau, t)+\int_{0}^{k_{\max }} p(k, x) \cdot x \cdot C(x, \tau, t) \cdot D(x) \cdot d x
$$

, where $C(k, \tau, t)$ is the dynamic concentration of the component with reactivity $k$ at axial position $\tau$ and time, $t$. The term on the left-hand side of Equation 2.1 denotes the accumulation of mass; 
the first term on the right-hand side denotes convective mass transport; the second term denotes the consumption of the species with reactivity $k$ due to cracking; and the third term is the generation of the species with reactivity $k$ due to cracking of the heavier species. $\tau$ is the residence time or the reciprocal of the Liquid Hourly Space Velocity (LHSV), defined by:

$$
\tau=\frac{\text { reactor volume }}{\text { Liquid volumetric flow rate }}=\frac{z}{v}=\frac{1}{L H S V}
$$

, where $\mathrm{z}$ is the reactor length, and $v$ is the liquid velocity.

The characterization parameter is the True Boiling Point (TBP) of each species in the mixture. $\theta$ is defined as a normalized TBP as shown in Equation 2.3.

$$
\theta=\frac{T B P_{i}-T B P(l)}{T B P(h)-T B P(l)} \quad \text { for } i=1,2,3, \ldots, n+1
$$

, where $T B P(l)$ and $T B P(h)$ are respectively the lowest and highest boiling point of any pseudocomponent in the mixture in kelvin.

The reactivity is represented by a power law function shown in Equation 2.4.

$$
\frac{k}{k_{\max }}=\theta^{1 / \alpha}
$$

$D(k)$ denotes a species-type distribution function with $\mathrm{N}$ being the number of compounds in the mixture as shown in Equation 2.5 [1].

$$
D(k)=\frac{N \alpha}{k_{\max }^{\alpha}} \mathrm{k}^{\alpha-1}
$$

The yield distribution function $p(k, x)$ that describes the formation of compounds of reactivity $k$ from the hydrocracking of compounds with reactivity $x$. Laxminarasimha et al. [5] observed that the skewed Gaussian-type distribution function as in Equation 2.6 is used to describe the yield distribution function. 


$$
p(k, x)=\frac{1}{S_{0} \sqrt{2 \pi}}\left\{\exp \left[-\left(\frac{(k / x)^{a_{0}}-0.5}{a_{1}}\right)^{2}\right]-\exp \left[-\left(\frac{0.5}{a_{1}}\right)^{2}\right]+\delta\left(1-\frac{k}{x}\right)\right\}
$$

$p(k, x)=0$ for $k \geq x$, as cracking is no more feasible [5]. For $k=0$, Equation 2.6 becomes:

$$
p(0, x)=\frac{\delta}{S_{0} \sqrt{2 \pi}}
$$

In order to satisfy the mass balance, Equation 2.8 is considered.

$$
\int_{0}^{x} p(k, x) \cdot D(x) \cdot d x=1
$$

Substituting Equation 2.6 into Equation 2.8, one obtains:

$$
S_{0}=\int_{0}^{x} \frac{1}{\sqrt{2 \pi}}\left\{\exp \left[-\left(\frac{(k / x)^{a_{0}}-0.5}{a_{1}}\right)^{2}\right]-\exp \left[-\left(\frac{0.5}{a_{1}}\right)^{2}\right]+\delta\left(1-\frac{k}{x}\right)\right\} D(k) \cdot d k
$$

The following boundary and initial conditions are considered:

$$
\begin{aligned}
& \text { at } \quad \mathrm{t}=0: \quad \tau=0, \quad \mathrm{C}=\mathrm{C}_{0} ; \quad \tau>0, C=0 \\
& \text { at } \quad \mathrm{t}>0: \quad \tau=\frac{L}{v}, \quad \frac{\partial \mathrm{C}}{\partial \tau}=0
\end{aligned}
$$

\subsubsection{Energy Balance}

Energy conservation is given by Equation 2.12 [7]:

$$
\frac{\partial T(\tau, t)}{\partial t}=-\frac{\partial \mathrm{T}(\tau, t)}{\partial \tau}+\frac{\int_{0}^{k_{\max }} \Delta H r(x) \cdot x \cdot C(k, \tau, t) \cdot D(x) \cdot d x}{\int_{0}^{k_{\max }} C p(x) \cdot C(k, \tau, t) \cdot D(x) \cdot d x}
$$

where $C p(x)$ is the specific heat capacity for every species $x ; \Delta H r(x)$ is the heat of cracking reaction for species $x . T(\tau, t)$ is the dynamic temperature at axial position $\tau$ and time $t$. The first 
term on the right-hand side denotes convective heat transfer; the second term denotes the heat requirement due to cracking.

Mohanty et al. [25] assumed the heat requirement to be for $42 \mathrm{~kJ} / \mathrm{mole}$ of hydrogen consumed during hydrocracking reaction as given by the following equation:

$$
(\Delta H r)_{i}=-\frac{42 \times 10^{3}}{2}\left(H_{2} C R\right)_{i}
$$

, where $\mathrm{H}_{2} \mathrm{CR}$ is the Hydrogen consumption per mass unit of a species and is given by:

$$
\left(H_{2} C R\right)_{i}=\left.\frac{w t i}{C H+1}\right|_{\text {product }}-\left.\frac{w t i}{C H+1}\right|_{\text {reactant }}
$$

, where $w t_{i}$ is the weight of each component in the mixture and $\mathrm{CH}$ is the carbon-to-hydrogen weight ratio, defined as follows [24-25]:

$\mathrm{CH}=8.7743 \times 10^{-10}\left[\exp \left(7.176 \times 10^{-3} T B P_{i}+30.06242 S G-7.35 \times 10^{-3} T B P_{i} \times S G\right)\right] T B P_{i}^{-0.98445} \mathrm{SG}^{-18.2753}$

Heat capacity and the associated parameters are given by:

$$
\begin{gathered}
C_{p}=b_{1}+\left(b_{21} \beta+b_{22} \beta^{2}\right) T+\left(b_{31} \beta+b_{32} \beta^{2}\right) T^{2} \\
b_{1}=24.5\left(a_{11} \beta+a_{12} \beta^{2}\right) \\
\mathrm{b}_{11}=-0.3416 \quad \mathrm{~b}_{12}=2.2671 \\
\mathrm{~b}_{21}=0.106 \quad \mathrm{~b}_{22}=-0.3874 \\
\mathrm{~b}_{31}=-0.000098231 \quad \mathrm{~b}_{32}=0.0004182 \\
\beta=\frac{\sum_{i=1}^{n} w t_{i} / M_{i}}{\sum_{i=1}^{n} w t_{i}} \\
S G_{i}=\frac{\sqrt[3]{T_{i b}}}{K_{a v g}} \\
K_{a v g}=\frac{\sqrt[3]{M e A B P}}{S G_{\text {avg }}}
\end{gathered}
$$


, where $M e A B P$ is the Mean Average Boiling Point of the whole mixture, SG is the specific gravity, $\beta$ being the similarity variable and $K_{\text {avg }}$ is the K-Watson for liquid bulk.

Initial and boundary conditions are given by:

$$
\begin{array}{cc}
\text { at } \quad \mathrm{t}=0: \quad \forall \tau, \quad \mathrm{T}=\mathrm{T}_{0} \\
\text { at } \quad \mathrm{t}>0: \quad \tau=\frac{L}{v}, \quad \frac{\partial \mathrm{T}}{\partial \tau}=0
\end{array}
$$

\subsection{Description of the dynamic model}

For solving the integro-differential Equations 2.1 and 2.12, they are discretized in spatial domain as shown in Equations 2.23 and 2.27, respectively. Equations $2.24-2.26$ denote the integrals that appear in Equation 2.23.

$$
\begin{aligned}
& \frac{\mathrm{d} C\left(k_{i}, \tau_{r}, t\right)}{\mathrm{d} t}=-\frac{C\left(k_{i}, \tau_{r}, t\right)-C\left(k_{i}, \tau_{r-1}, t\right)}{\Delta \tau}+C\left(k_{i}, \tau_{r}, t\right) \times\left[-k_{i}+I_{1 i}\right] \\
& +\sum_{j=i+1}^{n+1} C\left(k_{j}, \tau_{r}, t\right) \times I_{2 j}+\sum_{j=i+1}^{n} C\left(k_{j}, \tau_{r}, t\right) \times I_{3 j} \\
& \text { for } i=1,2, \ldots, n+1 \text { and } 0<\tau_{r}<\tau_{\max } \text {, where: } \\
& I_{1 i}=\int_{k_{i}}^{k_{i+1}} p\left(k_{i}, x\right) \cdot x \cdot\left(\frac{x-k_{i+1}}{k_{i}-k_{i+1}}\right) \cdot D(x) \cdot d x \\
& I_{2 j}=\int_{k_{j-1}}^{k_{j}} p\left(k_{i}, x\right) \cdot x \cdot\left(\frac{x-k_{j-1}}{k_{j}-k_{j-1}}\right) \cdot D(x) \cdot d x \\
& I_{3 j}=\int_{k_{j}}^{k_{j+1}} p\left(k_{i}, x\right) \cdot x \cdot\left(\frac{x-k_{j+1}}{k_{j}-k_{j+1}}\right) \cdot D(x) \cdot d x \\
& \frac{\mathrm{d} T\left(\tau_{r}, t\right)}{\mathrm{d} t}=-\frac{T\left(\tau_{r}, t\right)-T\left(\tau_{r-1}, t\right)}{\Delta \tau}+\frac{\int_{0}^{k_{\max }} \Delta H r(x) \cdot x \cdot C(k, \tau, t) \cdot D(x) \cdot d x}{\int_{0}^{k_{\max }} C p(x) \cdot C(k, \tau, t) \cdot D(x) \cdot d x}
\end{aligned}
$$


The algorithm used to solve the dynamic mass and energy balance is shown in Figure 2.1. The set of ODEs is solved using the Runge-Kutta method in Matlab. The numerical solution of Equations 2.23 and 2.27 requires solving the integrals first. This is done by using the quadrature algorithm to solve the Equations 2.9, $2.24-2.26$ since a Gaussian skewed function $p(k, x)$ is involved. The adaptive Lobatto quadrature (also known as Radau quadrature) is used in this work. Then Equations 2.23 and 2.27 are solved with respect to time.

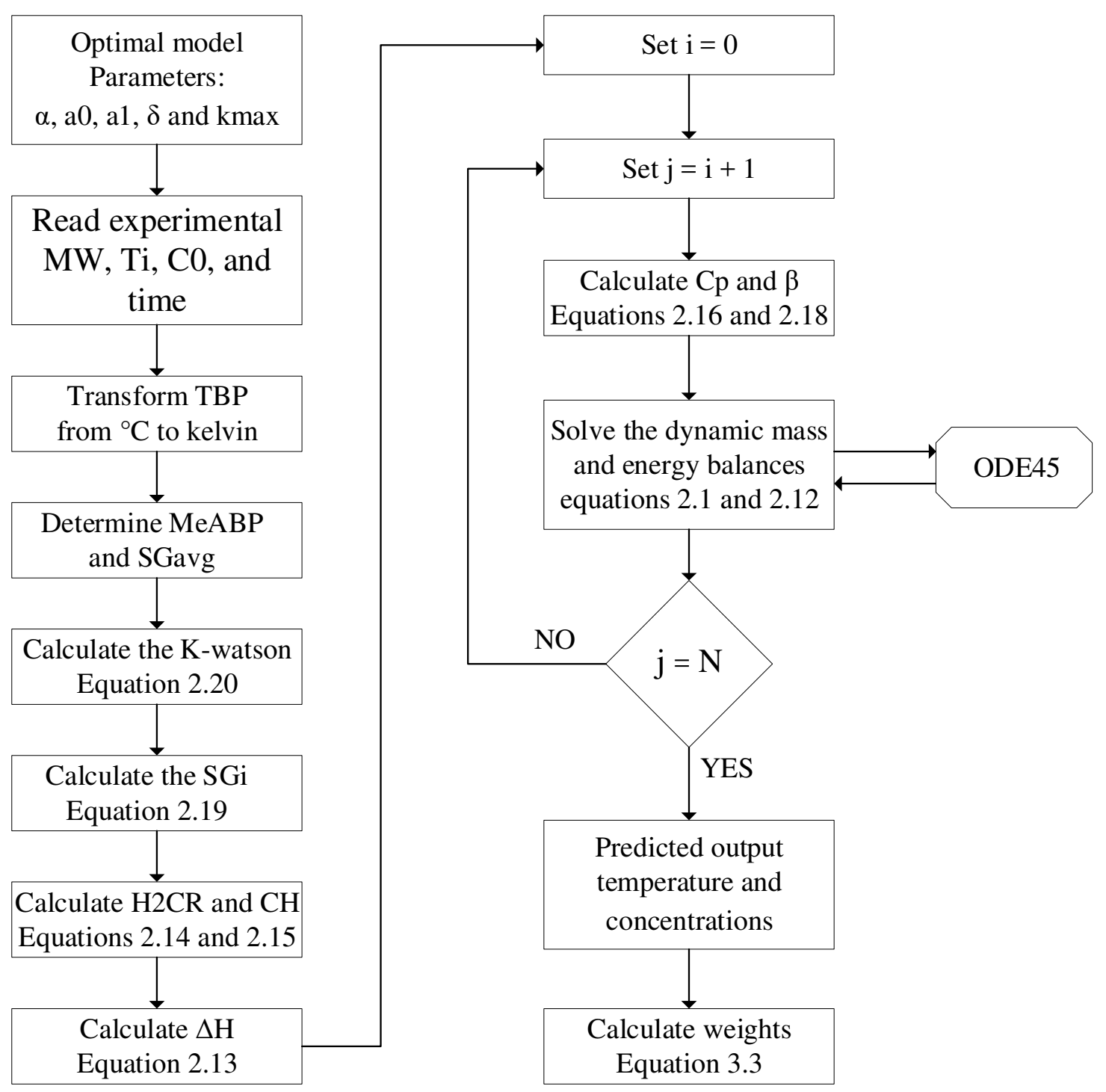

Figure 2.1: Algorithm for the dynamic mass and energy balance using continuous kinetic lumping 


\subsection{Results and discussion}

Figure 2.2 shows the cumulative weight fractions in 10 nodes of the reactor in the zdirection. The progression of the weights towards lighter components can clearly be seen.

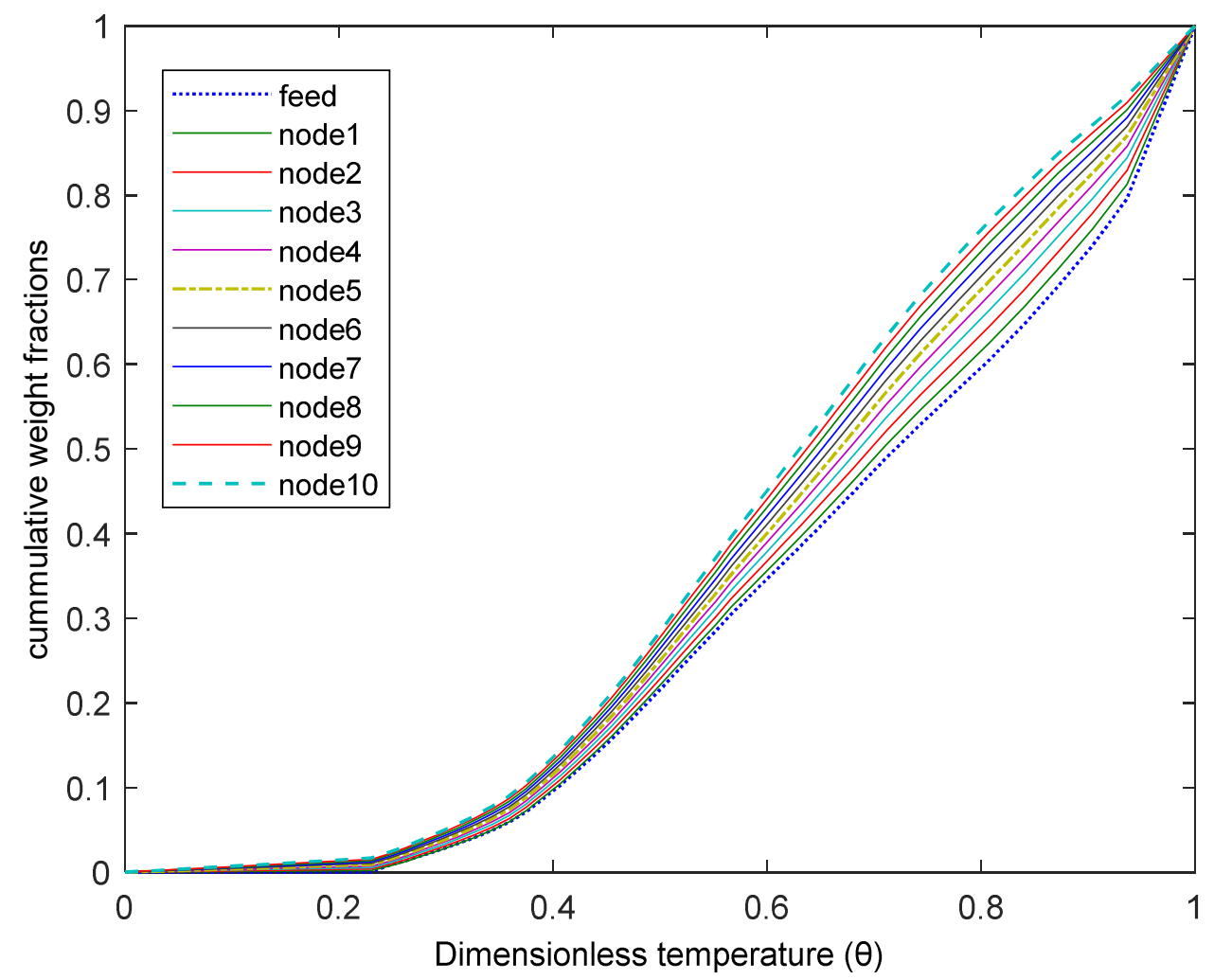

Figure 2.2: Cumulative dimensionless continuous concentration $(\mathrm{c}(\mathrm{t}, \tau, \mathrm{k}))$ for the ten nodes at $400{ }^{\circ} \mathrm{C}, 8.3$ $\mathrm{MPa}$ and LHSV of $0.5 \mathrm{~h}^{-1}$.

The cumulative weight fraction at different input temperatures is shown in Figure 2.3. It is clearly observed that as the input temperature is increased from $360{ }^{\circ} \mathrm{C}$ to $420{ }^{\circ} \mathrm{C}$, the weight of the product progressively moves towards the middle distillates and the light products. 


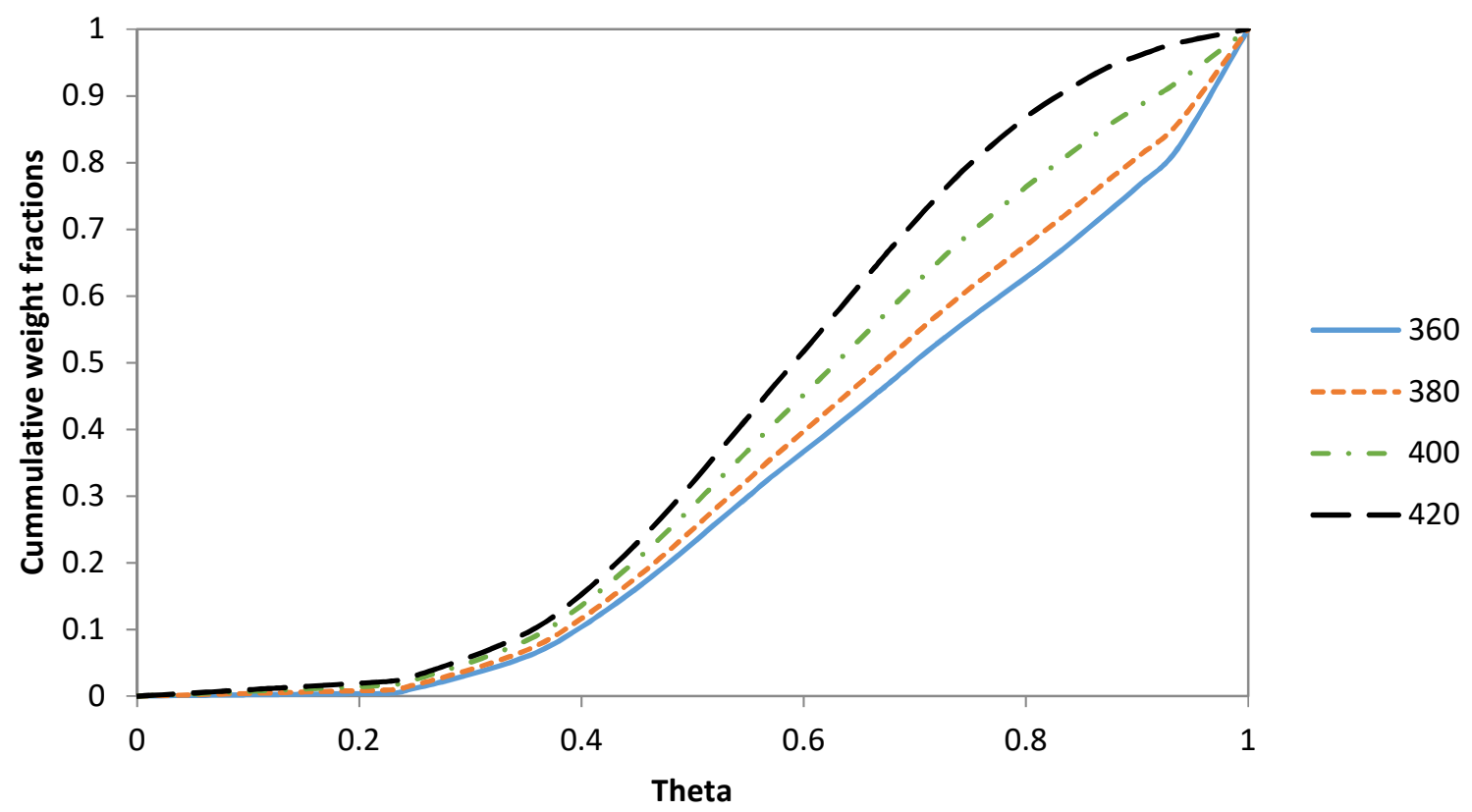

Figure 2.3: Cumulative weight fractions at different input Temperatures at $8.3 \mathrm{MPa}$ and LHSV of $0.5 \mathrm{~h}^{-1}$.

Figures 2.4 and 2.5 show the variation of temperature over time for 10 nodes in the reactor. It is observed from both figures that there is a time delay in the temperature response.

Elizalde et al. [7] suggested that the heat capacity can be kept constant since a varying heat capacity may not affect the temperature much. While this was found to be the case at lower temperatures such as in Figure 2.4, varying the heat capacity results in higher differences as opposed to when the heat capacity is kept constant as shown in Figure 2.5. 


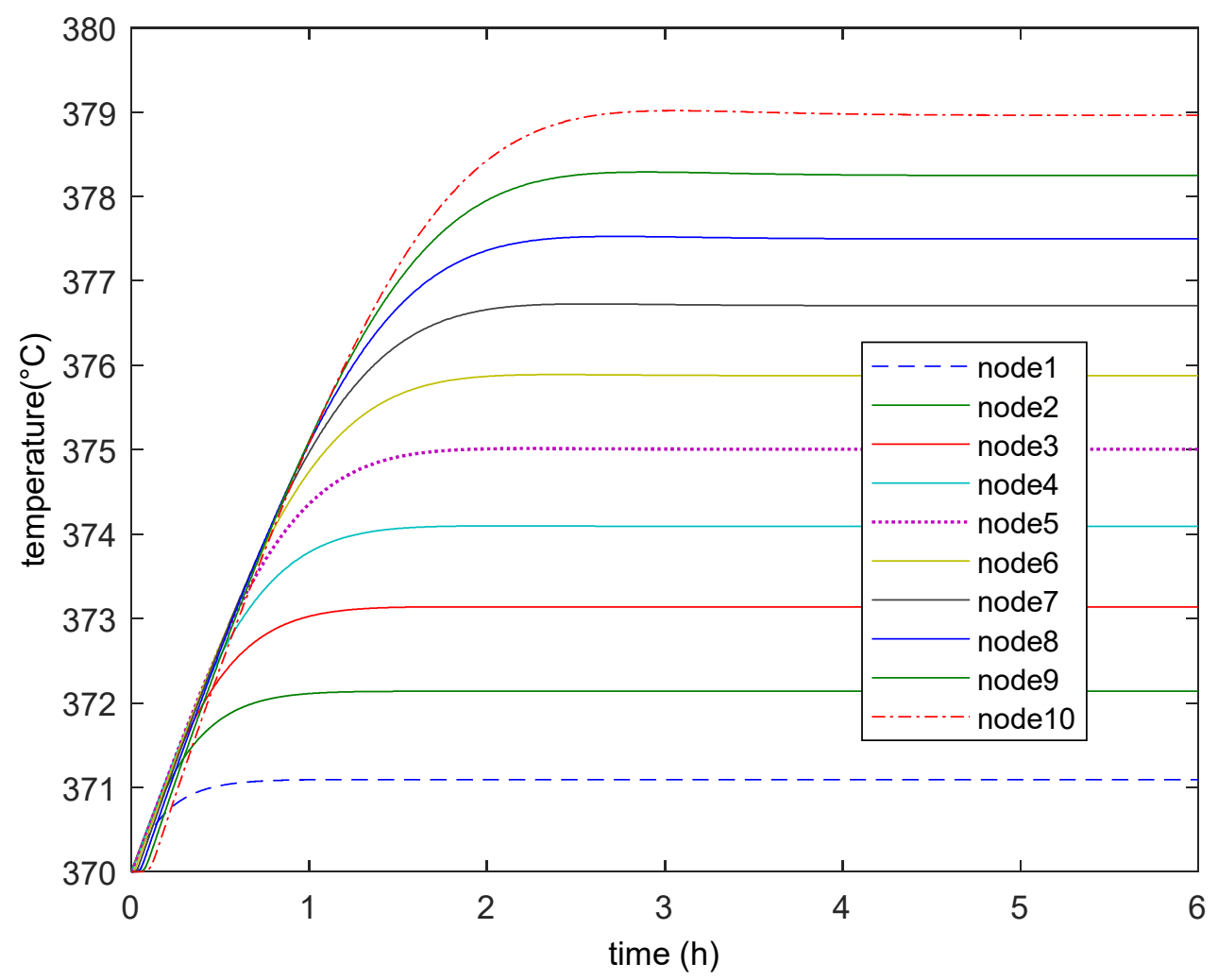

Figure 2.4: Temperature for the ten nodes at $370{ }^{\circ} \mathrm{C}, 8.3 \mathrm{MPa}$ and LHSV of $0.5 \mathrm{~h}^{-1}$.

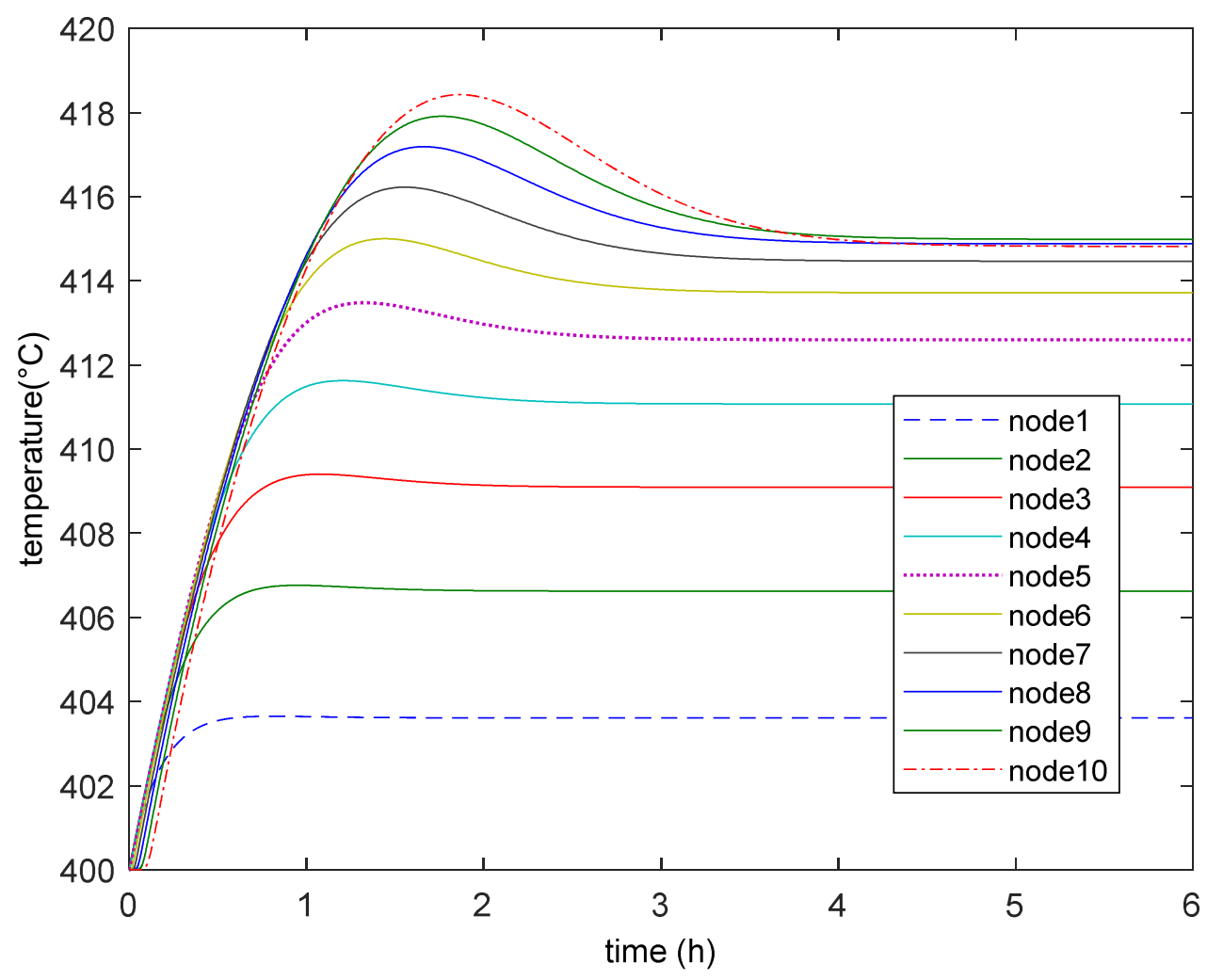

Figure 2.5: Temperature for the ten nodes at $400^{\circ} \mathrm{C}, 8.3 \mathrm{MPa}$ and LHSV of $0.5 \mathrm{~h}^{-1}$. 


\subsection{Conclusion}

In this chapter, a dynamic, non-isothermal model of a hydrocracker reactor is developed using the continuous kinetic lumping method in the Matlab simulation environment. The results compare well with the published literature [7]. The model can be used to predict spatial and temporal variation in the product compositions and temperatures and is therefore very useful for developing advanced control strategies. 


\section{CHAPTER 3: PARAMETER ESTIMATION}

\subsection{Introduction}

The continuous kinetic lumping model described in the previous chapter has a number of parameters that needs to be estimated. In this chapter, an algorithm for parameter estimation is developed. The Aspen Plus software is used to divide the mixture of hydrocarbons into lumps, which are then used in Matlab for estimating the model parameters. The results are then compared with the similar works in the open literature.

\subsection{Estimation of model parameters}

Kinetic model parameters are determined from the experimental data for different reaction temperatures under steady-state conditions. The Levenverg-Marquardt algorithm is used for this optimization. The algorithm to obtain these parameters is illustrated in Figure 3.1.

As noted earlier, as the integro-differential Equation 2.1 cannot be solved analytically, a numerical approach was devised which consist of first solving the integral part and then solving the ODEs. Under steady state conditions, Equation 2.23 can be rewritten as:

$$
\frac{\partial C\left(k_{i}, \tau_{r}\right)}{\partial \tau}=C\left(k_{i}, \tau_{r}\right) \cdot\left[-k_{i}+I_{1 i}\right]+\sum_{j=i+1}^{n+1} C\left(k_{j}, \tau_{r}\right) \cdot I_{2 j}+\sum_{j=i+1}^{n} C\left(k_{j}, \tau_{r}\right) \cdot I_{3 j}
$$

The RHS of Equation 3.1 can be expressed in more compact form by using the following matrix:

$$
B(k)=\left[\begin{array}{ccccccc}
-k_{1}+I_{11} & I_{22}+I_{32} & \cdots & I_{2 i}+I_{3 i} & \cdots & I_{2 n}+I_{3 n} & I_{2 n+1} \\
0 & -k_{2}+I_{12} & \cdots & I_{2 i}+I_{3 i} & \cdots & I_{2 n}+I_{3 n} & I_{2 n+1} \\
0 & 0 & \ddots & \vdots & \cdots & I_{2 n}+I_{3 n} & I_{2 n+1} \\
\vdots & \vdots & \vdots & -k_{i}+I_{1 i} & \cdots & \vdots & \vdots \\
\vdots & \vdots & \vdots & \vdots & \ddots & \vdots & \vdots \\
0 & 0 & \cdots & 0 & \cdots & -k_{n}+I_{1 n} & I_{2 n+1} \\
0 & 0 & \cdots & 0 & \cdots & 0 & -k_{n+1}
\end{array}\right]
$$

To obtain the weights at any desired residence time, Equation 3.3 can be solved: 


$$
w t(\tau)=A(k) \cdot C(k, \tau)
$$

, where $A(k)$ is expressed as:

$$
A(k)=\left[\begin{array}{ccccccc}
a_{11} & a_{12} & 0 & 0 & \cdots & 0 & 0 \\
0 & a_{21} & a_{22} & 0 & \cdots & 0 & 0 \\
0 & 0 & a_{31} & a_{32} & \cdots & 0 & 0 \\
\vdots & \vdots & \vdots & \vdots & \ddots & \vdots & \vdots \\
0 & 0 & 0 & \cdots & \cdots & a_{n 1} & a_{n 2}
\end{array}\right]
$$

, where:

$$
\begin{aligned}
a_{i 1} & =\frac{1}{k_{i}-k_{i+1}} \frac{n \cdot \alpha}{k_{\max }^{\alpha}}\left[\left(\frac{k_{i+1}^{\alpha+1}}{\alpha+1}-\frac{k_{i+1}^{\alpha+1}}{\alpha}\right)-\left(\frac{k_{i}^{\alpha+1}}{\alpha+1}-k_{i+1} \frac{k_{i}^{\alpha}}{\alpha}\right)\right] \\
a_{i 2} & =\frac{1}{k_{i+1}-k_{i}} \frac{n \cdot \alpha}{k_{\max }^{\alpha}}\left[\left(\frac{k_{i+1}^{\alpha+1}}{\alpha+1}-k_{i} \frac{k_{i+1}^{\alpha}}{\alpha}\right)-\left(\frac{k_{i}^{\alpha+1}}{\alpha+1}-\frac{k_{i}^{\alpha+1}}{\alpha}\right)\right]
\end{aligned}
$$

Since we have the initial weight fractions $w t(0)$ and $A(k)$, the initial concentration $c(k, 0)$ is obtained by solving Equation 3.7:

$$
\begin{gathered}
\min J(c(k, 0))=\sum_{i=1}^{n}\left[c\left(k_{i}, 0\right)-c\left(k_{i+1}, 0\right)\right]^{2} \\
\text { subject to } \\
\alpha>0 \text { and } k_{\max }>0 \\
c\left(k_{i}, 0\right) \geq 0
\end{gathered}
$$

The objective function used for parameter estimation is:

$$
\begin{aligned}
& \min J(w t(\theta))=\sum_{i=1}^{n}\left[\left.w t_{i}^{\text {exp }}\right|_{\tau}-\left.w t_{i}^{\text {calc }}\right|_{\tau}\right]^{2} \\
& \text { subject to } \\
& \alpha>0, a_{0}>0 a_{1}>0, \delta>0 \text { and }, k_{\max }>0 \\
& \sum_{i=1}^{n} w t_{i}=1
\end{aligned}
$$


The optimization problem is solved by using successive quadratic programming (SQP) approach.

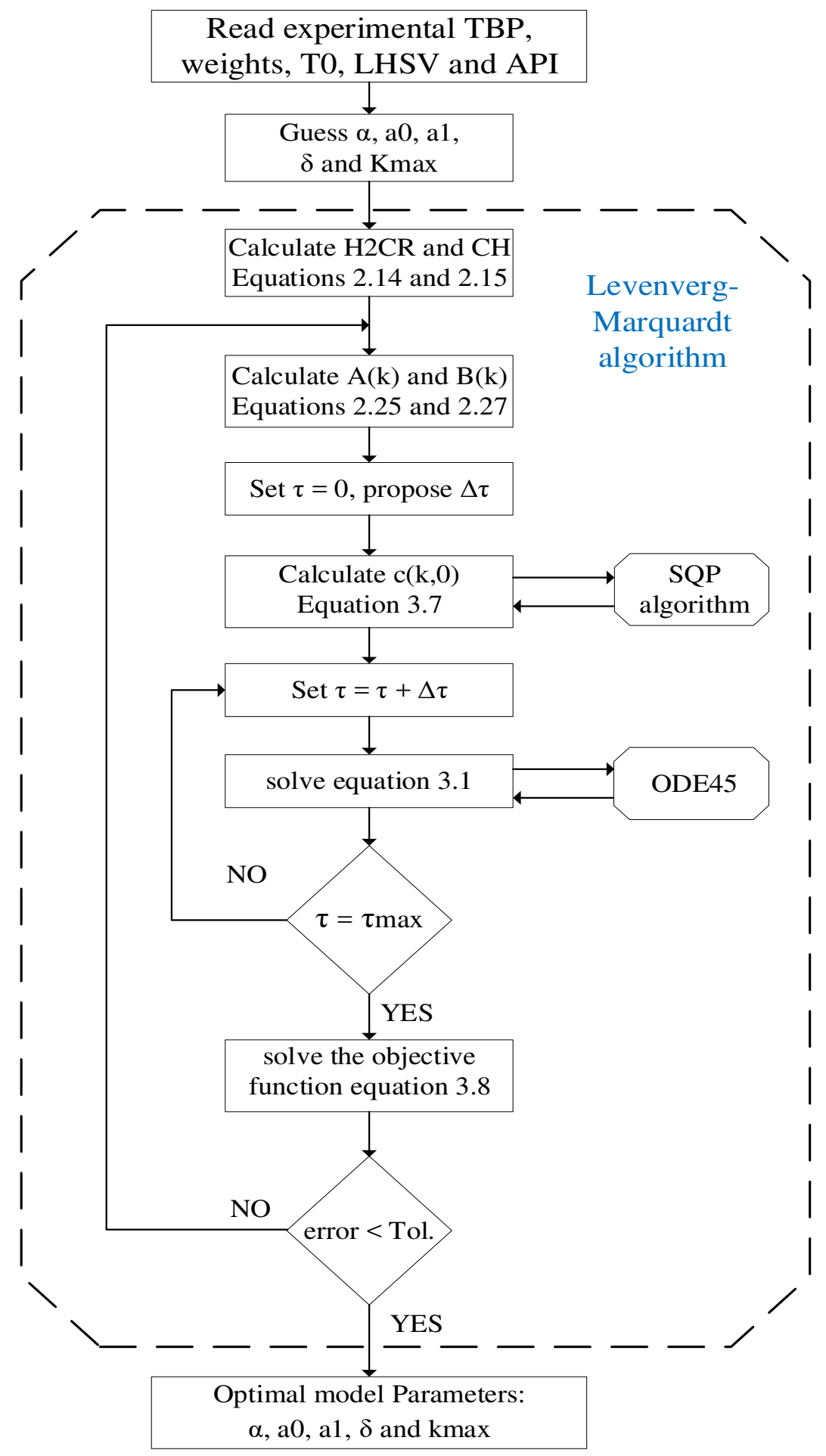

Figure 3.1: Algorithm for parameter estimation for the continuous kinetic lumping model 


\subsection{Experimental data}

The data used for this work were obtained from Elizalde and Ancheyta [10]. Maya crude oil with an $A P I$ of 21 was used for these experiments. Experimental data were collected from a bench-scale unit at the following reaction conditions: $8.3 \mathrm{MPa}, 400{ }^{\circ} \mathrm{C}, 0.5 \mathrm{~h}^{-1}$ of $\mathrm{LHSV}$ and $\mathrm{H}_{2}$ to-oil ratio of $5000 \mathrm{ft}^{3} / \mathrm{bbl}$ oil. Characterization of the feed and liquid products was carried out using the ASTM 5307 method which can be applied to temperatures as high as $538^{\circ} \mathrm{C}$. Light gases were not present in the feedstock; the distillation data were collected for every $5 \%$ mass evaporated starting from the initial boiling point (IBP) of $30.21{ }^{\circ} \mathrm{C}$ to a final boiling point (FBP) of 533.84 ${ }^{\circ} \mathrm{C}$. Light gases and hydrocracked products were obtained. Both products were quantified and analyzed separately in order to obtain the normalized composition at the outlet of the reactor. Appendix 1 [10] provides the composition of the feed and the hydrocracked products.

\subsection{Separation of Experimental data into lumps}

It has been observed that if less than 40 component lumps are used for the initial dimensionless concentration $(c(k, 0))$, the results are not satisfactory [10]. The feed and products are segmented into 42 lumps by using Aspen Properties based on their TBP (weight basis). Table 1 depicts the weight fractions for each of the 42 components with respect to their TBPs. It is observed that after cracking, gases are found in the products. Table 1 also shows the different commercial products corresponding to the different weight fractions divided according to their initial boiling points, corresponding to the IBPs. 
Table 1: Lumps of Feed and hydrocracked products with a FBP of $704{ }^{\circ} \mathrm{C}$

\begin{tabular}{|c|c|c|c|c|}
\hline $\begin{array}{l}\text { Commercial } \\
\text { products }\end{array}$ & $\begin{array}{l}\text { Pseudo-components } \\
\text { (n) }\end{array}$ & $\operatorname{IBP}\left({ }^{\circ} \mathbf{C}\right)$ & $\begin{array}{c}\text { Initial cumulative } \\
\text { weight fractions (Feed) }\end{array}$ & $\begin{array}{l}\text { Final cumulative weight } \\
\text { fractions (products) }\end{array}$ \\
\hline \multirow{5}{*}{ Gases } & 1 & -161.55 & 0 & 0.0012 \\
\hline & 2 & -88.55 & 0 & 0.0014 \\
\hline & 3 & -59.65 & 0 & 0.0165 \\
\hline & 4 & -42.05 & 0 & 0.0027 \\
\hline & 5 & -0.45 & 0 & 0.0004 \\
\hline \multirow{5}{*}{ Gasoline } & 6 & 38 & 0.0082 & 0.0074 \\
\hline & 7 & 52 & 0.0057 & 0.002 \\
\hline & 8 & 66 & 0.006 & 0.0026 \\
\hline & 9 & 79 & 0.0065 & 0.0038 \\
\hline & 10 & 93 & 0.0069 & 0.0051 \\
\hline \multirow{6}{*}{ kerosene } & 11 & 107 & 0.0075 & 0.0191 \\
\hline & 12 & 121 & 0.0083 & 0.0149 \\
\hline & 13 & 135 & 0.0097 & 0.0122 \\
\hline & 14 & 149 & 0.0125 & 0.0153 \\
\hline & 15 & 163 & 0.0157 & 0.0174 \\
\hline & 16 & 177 & 0.0161 & 0.0204 \\
\hline \multirow{7}{*}{ diesel } & 17 & 191 & 0.0166 & 0.0244 \\
\hline & 18 & 204 & 0.0183 & 0.0255 \\
\hline & 19 & 218 & 0.019 & 0.0273 \\
\hline & 20 & 232 & 0.0202 & 0.0286 \\
\hline & 21 & 246 & 0.021 & 0.0275 \\
\hline & 22 & 260 & 0.0216 & 0.0254 \\
\hline & 23 & 274 & 0.0221 & 0.0252 \\
\hline \multirow{7}{*}{ Fuel oil } & 24 & 288 & 0.0215 & 0.025 \\
\hline & 25 & 302 & 0.0211 & 0.0269 \\
\hline & 26 & 316 & 0.0206 & 0.0289 \\
\hline & 27 & 329 & 0.02 & 0.0269 \\
\hline & 28 & 343 & 0.0199 & 0.0258 \\
\hline & 29 & 357 & 0.02 & 0.0249 \\
\hline & 30 & 371 & 0.0201 & 0.0246 \\
\hline \multirow{12}{*}{ Residue } & 31 & 385 & 0.0205 & 0.025 \\
\hline & 32 & 399 & 0.0209 & 0.0254 \\
\hline & 33 & 413 & 0.021 & 0.027 \\
\hline & 34 & 427 & 0.0416 & 0.0489 \\
\hline & 35 & 454 & 0.0399 & 0.0438 \\
\hline & 36 & 482 & 0.0382 & 0.0422 \\
\hline & 37 & 510 & 0.0382 & 0.0412 \\
\hline & 38 & 538 & 0.0419 & 0.0409 \\
\hline & 39 & 566 & 0.0444 & 0.0406 \\
\hline & 40 & 593 & 0.0484 & 0.0404 \\
\hline & 41 & 621 & 0.0553 & 0.0404 \\
\hline & 42 & 649 & 0.2042 & 0.0748 \\
\hline
\end{tabular}




\subsection{Model validation}

Figure 3.2 shows a comparison of the cumulative weights of the feed in the model versus the experimental data. Figures 3.3 and 3.4 compare model results against the experimental data for the cumulative weights of the components in the products. It is observed that the model results are in good agreement with the experimental data.

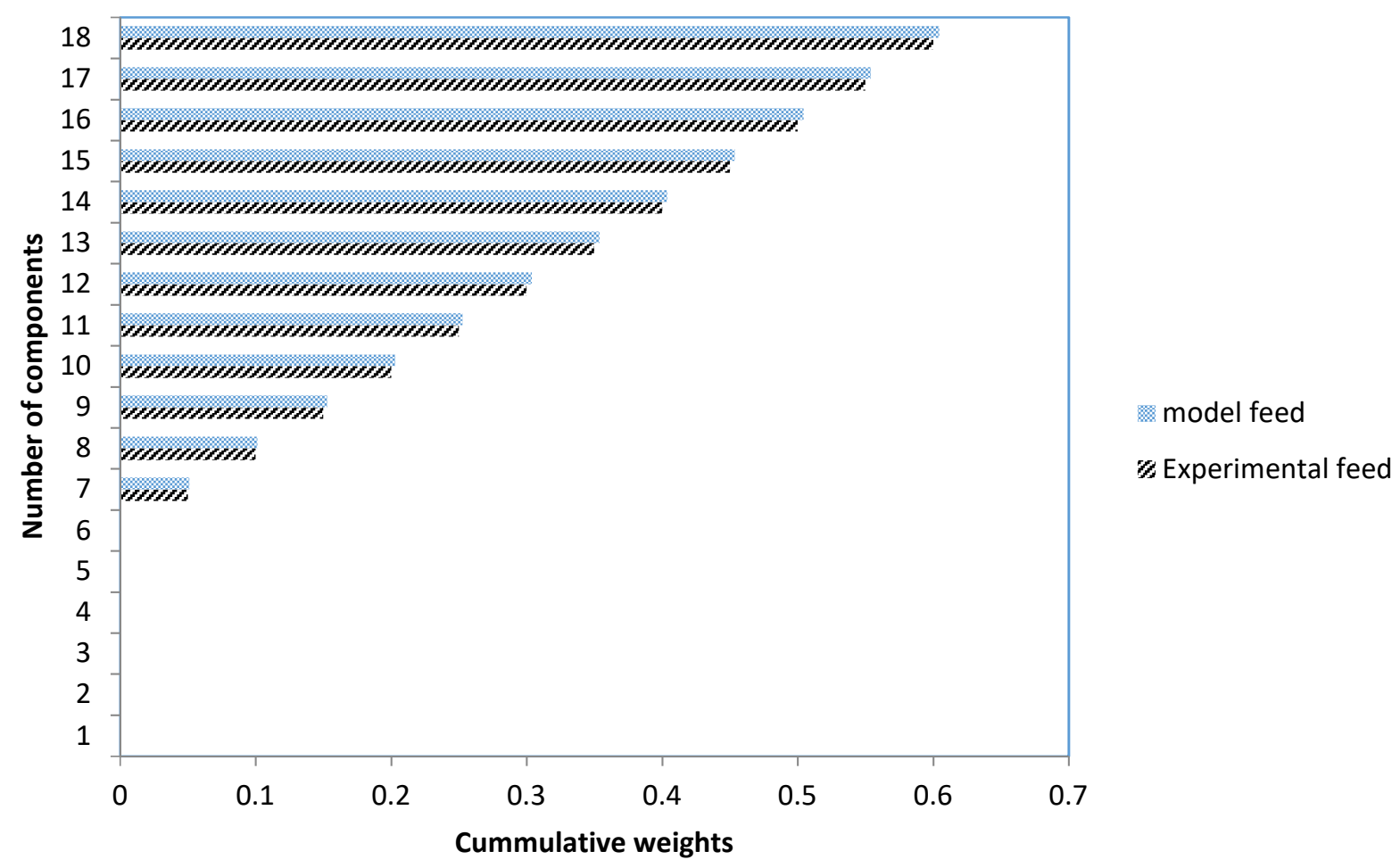

Figure 3.2: Comparison of experimental data versus model results for the feed $\left(\mathrm{T}=400{ }^{\circ} \mathrm{C}, \mathrm{P}=8.3 \mathrm{MPa}\right.$, LHSV $\left.=0.5 h^{-1}\right)$ 


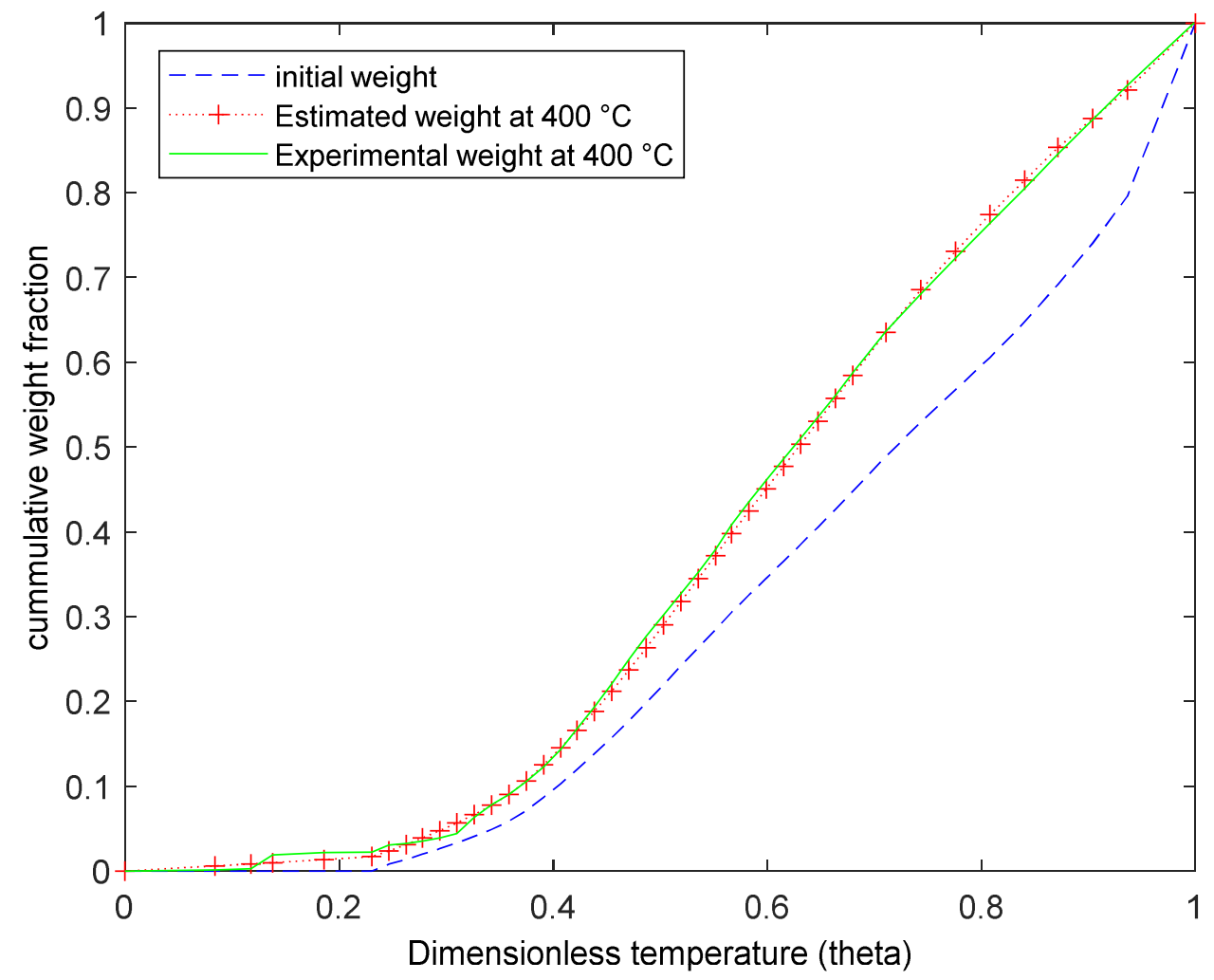

Figure 3.3: Comparison of experimental data versus model results for the product $\left(\mathrm{T}=400{ }^{\circ} \mathrm{C}, \mathrm{P}=8.3 \mathrm{MPa}\right.$, LHSV $=0.5 h^{-1}$ )

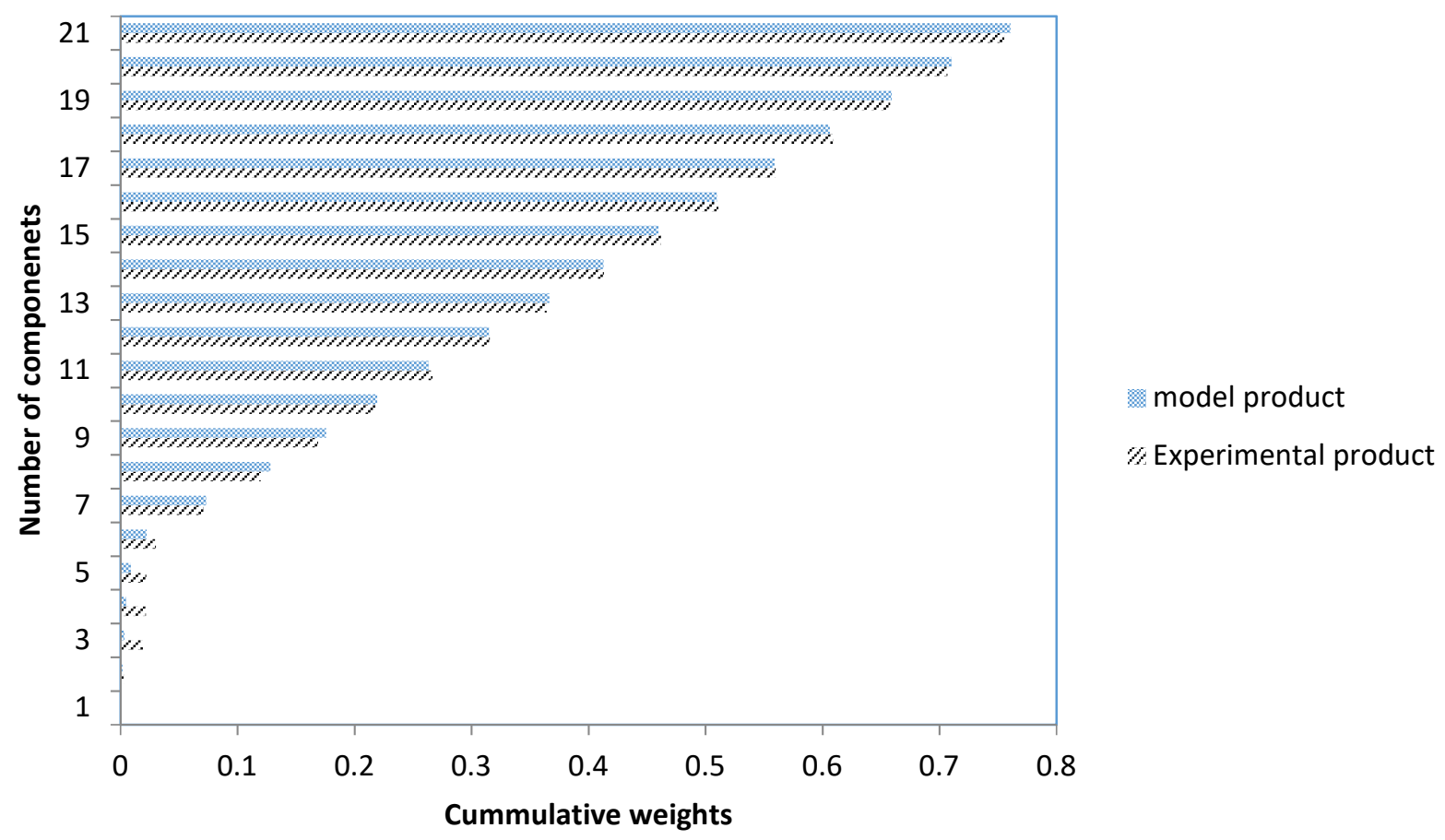

Figure 3.4: Comparison between the model results and experimental data for the cumulative weights of components at $8.3 \mathrm{MPa}, 400{ }^{\circ} \mathrm{C}$ and LHSV of $0.5 \mathrm{~h}^{-1}$. 
The continuous kinetic lumping model has 5 parameters. These parameters, $\alpha, \mathrm{a}_{1}, \mathrm{a}_{0}, \delta$ and $\mathrm{k}_{\max }$ were estimated at four different temperatures: $360{ }^{\circ} \mathrm{C}, 380{ }^{\circ} \mathrm{C}, 400{ }^{\circ} \mathrm{C}$, and $420{ }^{\circ} \mathrm{C}$. An almost linear dependence is observed between $\alpha$, a0, and $\delta$ with temperature (Figures $3.5 \mathrm{a}, \mathrm{b}$, and d). Parameter $\mathrm{a}_{1}$ appears to be a weak function of temperature (Figure $3.5 \mathrm{c}$ ); while $\mathrm{k}_{\max }$ (Figure 3.5 e) shows an exponential relation with temperature. The estimates obtained in this work are very similar to those obtained in literature [7]. 
d.

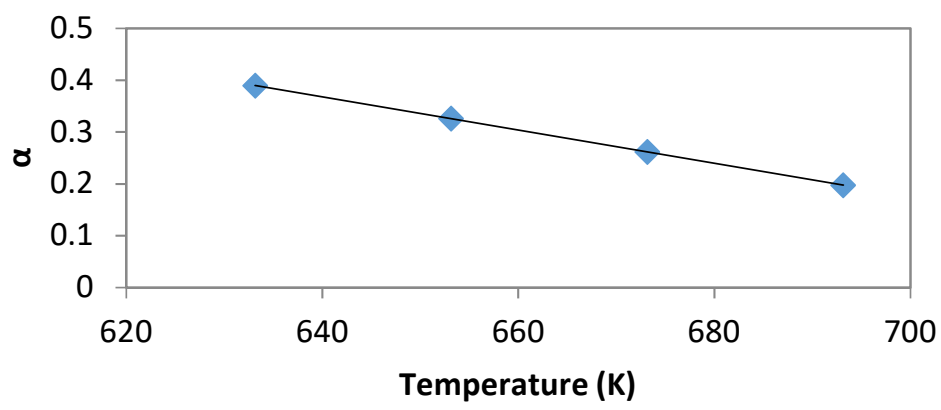

b.

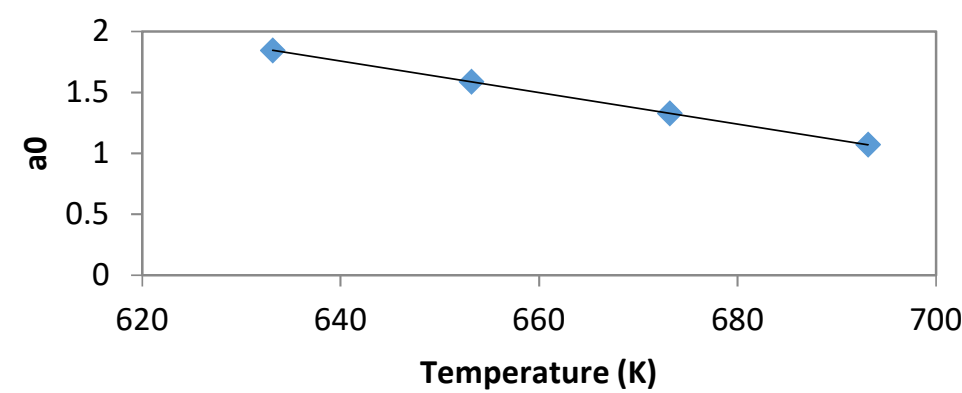

c.

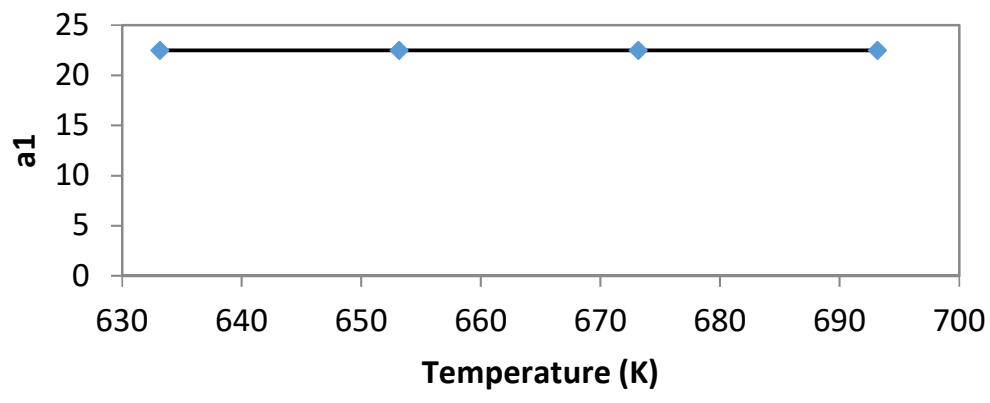

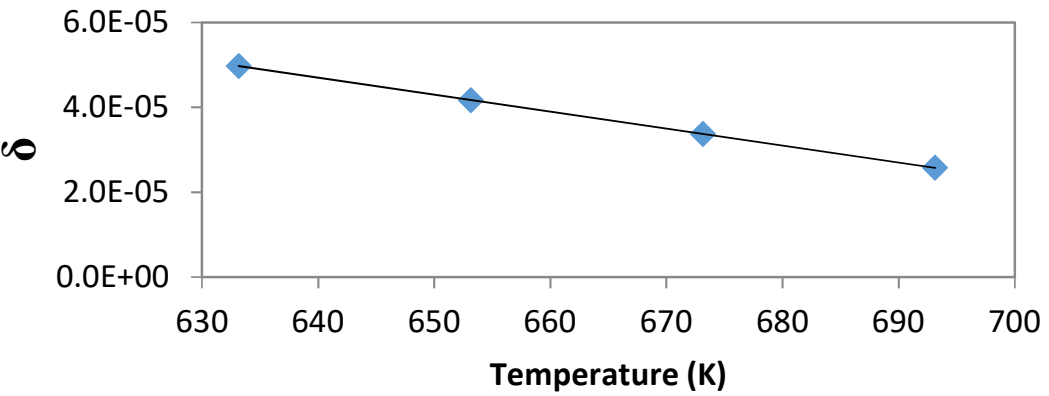

e.

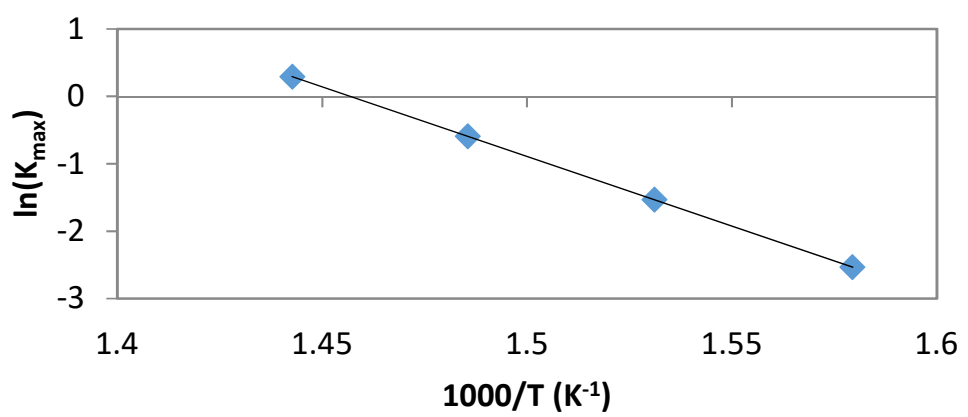

Figures 3.5: Dependence of the continuous kinetic model parameters with temperature at $8.3 \mathrm{MPa}$ and LHSV of $0.5 \mathrm{~h}-1$. 


\subsection{Conclusion}

The results obtained from parameter estimation in this chapter are comparable with the literature [24] [10]; since the results were very similar as depicted by Figures 3.5 a-e. The Aspen Plus software is used to divide the mixture of hydrocarbons into 42 lumps, thereby increasing the accuracy of our results. The parameters estimated are found to be in good agreement with literature, while the computational time in Matlab is also improved, since Aspen Plus could be leveraged to obtain the desired lumps, rather than extrapolations typically done in the literature. 


\section{CHAPTER 4: CONTROLLER DEVELOPMENT}

\subsection{Introduction}

Two types of quadratic dynamic matrix control (QDMC) are developed in the course of this research. Firstly, SISO QDMC is developed, where both servo response and disturbance rejection performances are studied; followed by the MIMO QDMC. The PRBS sequence is used for the system identification of the hydrocracker process.

The hydrocracker being controlled has a height of $25.21 \mathrm{~m}$ and diameter of $4.734 \mathrm{~m}$. Under steady-state conditions, the hydrocracker operates with a LHSV of 0.5 , a pressure of $8.9 \mathrm{MPa}$ and a temperature of $400{ }^{\circ} \mathrm{C}$.

\subsection{QDMC algorithm}

A schematic of a typical unit step-response is shown in Figure 4.1 [27-28].
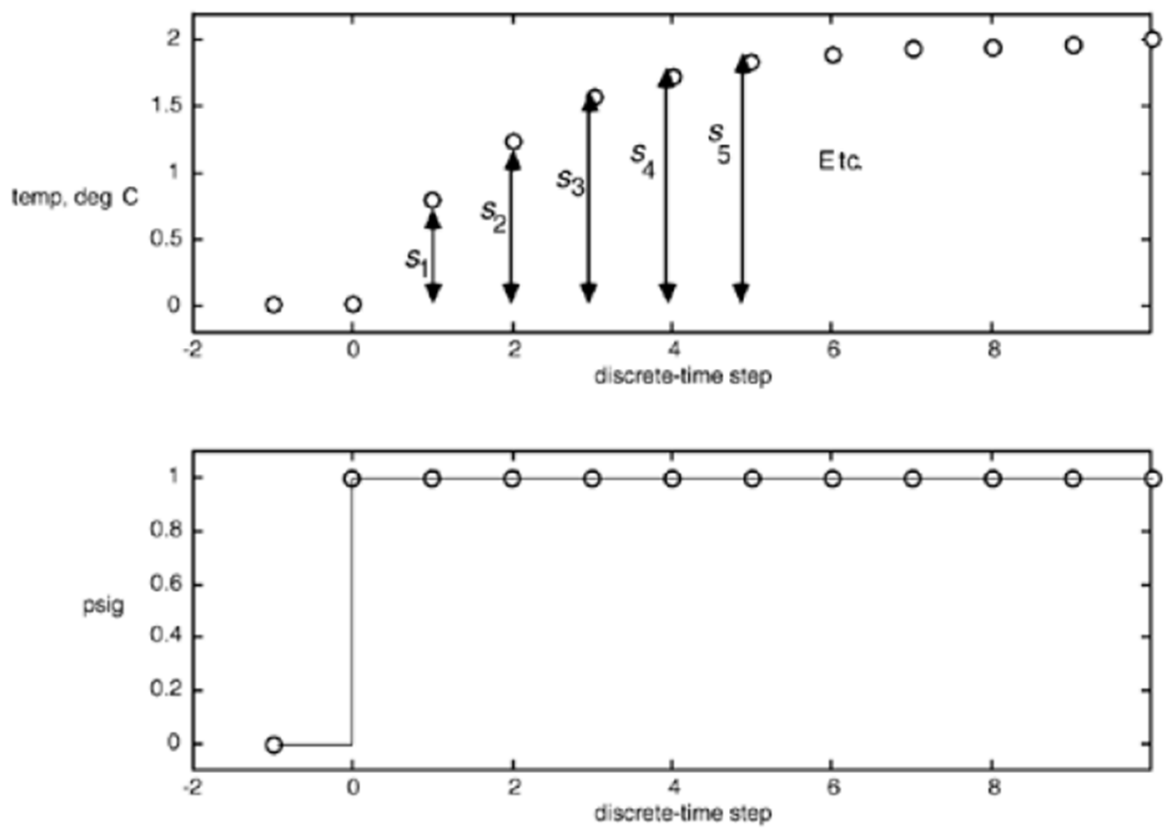

Figure 4.1: Illustration of step response parameter identification

Super-positioning all the inputs, the output of the step $k$ can be found by: 


$$
\begin{gathered}
\mathrm{y}_{k}=\sum_{i=1}^{\infty} \mathrm{S}_{i} \Delta u_{k-i}+\cdots+\mathrm{S}_{N-1} \Delta u_{k-N-i}+\mathrm{S}_{N} \Delta u_{k-N}+\cdots+\mathrm{S}_{N} \Delta u_{k-\infty} \\
\Rightarrow \mathrm{y}_{k}=\mathrm{S}_{N} \Delta u_{k-N}+\sum_{i=1}^{N-1} \mathrm{~S}_{i} \Delta u_{k-i}
\end{gathered}
$$

, where $\mathrm{y}_{k}$ are the output step responses, and $\mathrm{S}_{i}$ represents the step response coefficient for the $i^{\text {th }}$ sample time. $\Delta u_{k}$ being the input control moves at discrete time $k$.

The output model prediction:

$$
\hat{\mathrm{y}}_{k}=\mathrm{S}_{N} \Delta u_{k-N}+\sum_{i=1}^{N-1} \mathrm{~S}_{i} \Delta u_{k-i}
$$

in which $\Delta u_{k-N}$ is the manipulated input $N$ steps in the past.

$$
\mathrm{d}_{k}=\mathrm{y}_{k}-\hat{\mathrm{y}}_{k}
$$

, where $\mathrm{d}_{k}$ is the discrepancy in the model prediction, which is assumed to be due to unmodeled disturbances.

The corrected predicted output is then equal to:

$$
\hat{\mathrm{y}}_{k}^{c}=\hat{\mathrm{y}}_{k}+\mathrm{d}_{k}
$$

The DMC can then be represented in matrix form as: 


$$
\begin{gathered}
{\left[\begin{array}{c}
\hat{\mathrm{y}}_{k+1}^{c} \\
\hat{\mathrm{y}}_{k+2}^{c} \\
\vdots \\
\hat{\mathrm{y}}_{k+j}^{c} \\
\vdots \\
\hat{\mathrm{y}}_{k+p}^{c}
\end{array}\right]=} \\
+\left[\begin{array}{cccccc}
\mathrm{S}_{1} & 0 & 0 & \cdots & 0 & 0 \\
\mathrm{~S}_{2} & \mathrm{~S}_{1} & 0 & \cdots & 0 & 0 \\
\vdots & & & & & \\
\mathrm{S}_{j} & \mathrm{~S}_{j-1} & \mathrm{~S}_{j-2} & \cdots & \cdots & \mathrm{S}_{j-M+1} \\
\vdots & \vdots & \vdots & & & \vdots \\
\mathrm{S}_{p} & \mathrm{~S}_{p-1} & \mathrm{~S}_{p-2} & \cdots & \cdots & \mathrm{S}_{p-M+1}
\end{array}\right]\left[\begin{array}{c}
\Delta u_{k} \\
\Delta u_{k+1} \\
\vdots \\
\Delta u_{k+M-2} \\
\Delta u_{k+M-1}
\end{array}\right] \\
+\left[\begin{array}{cccccc}
\mathrm{S}_{2} & \mathrm{~S}_{3} & \mathrm{~S}_{4} & \cdots & \mathrm{S}_{N-2} & \mathrm{~S}_{N-1} \\
\mathrm{~S}_{3} & \mathrm{~S}_{4} & \mathrm{~S}_{5} & \cdots & \mathrm{S}_{N-1} & 0 \\
\vdots & \vdots & & & 0 & 0 \\
\mathrm{~S}_{j+1} & \mathrm{~S}_{j+2} & \cdots & \mathrm{S}_{N-1} & 0 & 0 \\
\vdots & \vdots & \vdots & & & \vdots \\
\mathrm{S}_{p+1} & \mathrm{~S}_{p+2} & \cdots & 0 & \cdots & 0
\end{array}\right]\left[\begin{array}{c}
\Delta u_{k-1} \\
\Delta u_{k-2} \\
\vdots \\
\Delta u_{k-N+3} \\
\Delta u_{k-N+2}
\end{array}\right] \\
+\mathrm{S}_{N}\left[\begin{array}{c}
\Delta u_{k-N+1} \\
\Delta u_{k-N+2} \\
\vdots \\
\Delta u_{k-N+P}
\end{array}\right]+\left[\begin{array}{c}
\mathrm{d}_{k+1} \\
\mathrm{~d}_{k+2} \\
\vdots \\
\mathrm{d}_{k+P}
\end{array}\right]
\end{gathered}
$$

Equation 4.6 can be written using the matrix-vector notation as:

$$
\hat{Y}^{c}=\mathrm{S}_{f} \Delta u_{f}+\mathrm{S}_{\text {past }} \Delta u_{\text {past }}+\mathrm{S}_{N} u_{P}+\hat{d}
$$

, where $\hat{Y}^{c}$ is the corrected predicted outputs; on the right-hand side, the first term are the effects of the current and future moves, the second and third terms are the effect of the past moves, the fourth term is the predictive disturbance.

Equation 4.7 can be re-written as:

$$
\hat{Y}^{c}=\mathrm{S}_{f} \Delta u_{f}+f
$$

, where $f$, is the free response of the "corrected - predicted output", as shown below:

$$
f=\mathrm{S}_{\text {past }} \Delta u_{\text {past }}+\mathrm{S}_{N} u_{P}+\hat{d}
$$

Since we desire that the outputs should not exceed certain limits, the outputs are constrained.

$$
y_{\min } \leq \hat{y}_{k+i}^{c} \leq y_{\max }
$$


Substituting Equation 4.8 into 4.10, we obtain:

$$
y_{\min }-f \leq \mathrm{S}_{f} \Delta u_{f} \leq y_{\max }-f
$$

The manipulated inputs and their control moves are also constrained:

$$
\begin{gathered}
u_{\min } \leq u_{k+i} \leq u_{\max } \\
\Delta u_{\min } \leq \Delta u_{k+i} \leq \Delta u_{\max }
\end{gathered}
$$

A quadratic programming problem stated using the shorthand matrix - vector notation below, is then solved

$$
\begin{aligned}
& \min _{\Delta u_{f}} \Phi=\frac{1}{2} \Delta u_{f}^{T} H \Delta u_{f}+C^{T} \Delta u_{f} \\
& \text { s.t. } \quad A \Delta u_{f} \geq b \\
& \qquad \Delta u_{\min } \leq \Delta u_{f} \leq \Delta u_{\max }
\end{aligned}
$$

With:

$$
H=S_{f}^{T} S_{f}+W \quad \text { and } \quad C^{T}=-E^{T} S_{f}
$$

, where $W$ is the weight for each of the input control moves, $A$ is the matrix of the constraints and $b$ the projected deviations of constraint variables and their limits.

\subsection{System Identification}

This subsection describes the series of steps involved in the development of the data driven dynamic model of the hydrocracker. The obtained process model is then embedded into the QDMC. The step size used for the system identification is 60 second. The characteristics of the hydrocracker reactor are same as for the SISO control. 
System identification is undertaken using a pseudo random binary signal (PRBS) [20-21]. A PRBS is a two-level signal, represented by 0's or 1's generated with shift registers, which is given by Equation 4.15:

$$
\begin{aligned}
& u(t)=\operatorname{rem}(A(q) u(t), 2) \\
& u(t)=\operatorname{rem}\left(a_{1} u(t-1)+\cdots+a_{n} u(t-n), 2\right)
\end{aligned}
$$

, where $\operatorname{rem}(m, 2)$ is the remainder of $m$ divided by 2 , which provides a binary value.

The PRBS is a deterministic signal with a length $N_{s}$, as described by Equation 4.16:

$$
\begin{gathered}
N_{S}=2^{n_{r}}-1 \\
N_{S_{1}} \geq \frac{\pi 6 \tau_{d o m}^{H}}{T_{S w}} \\
N_{S_{2}} \geq p \times D \\
N_{S}=\max \left(N_{S_{1}}, N_{S_{2}}\right)
\end{gathered}
$$

, where $n_{r}, \tau_{d o m}^{L}$, and $\tau_{d o m}^{H}$ denote the number of shift registers, slowest and fastest time constants, respectively. The time constants are estimated by using a process model, with $\tau_{d o m}^{L}=0.11 \mathrm{hr}$, and $\tau_{d o m}^{H}=0.23 \mathrm{hr}$ Lack of cross-correlation between the signals is ensured by applying a delay $D$ before implementing the subsequent variable till all $p$ are exhausted. The delay is calculated by taking into consideration the switching time $T_{S w}$ as shown in Equation 4.20. The overall time required to implement the signal for a single variable is obtained by multiplying the signal length $N_{S}$ with the switching time, as shown in Equation 4.22.

$$
\begin{gathered}
D=\frac{T_{\text {settle }}^{\max }}{T_{s w}} \\
T_{s w} \leq \frac{2.8 \tau_{\text {dom }}^{L}}{2}
\end{gathered}
$$




$$
t_{\text {final }}=T_{s w} N_{s}
$$

Figure 4.2 presents the initially generated designed PRBS signal.

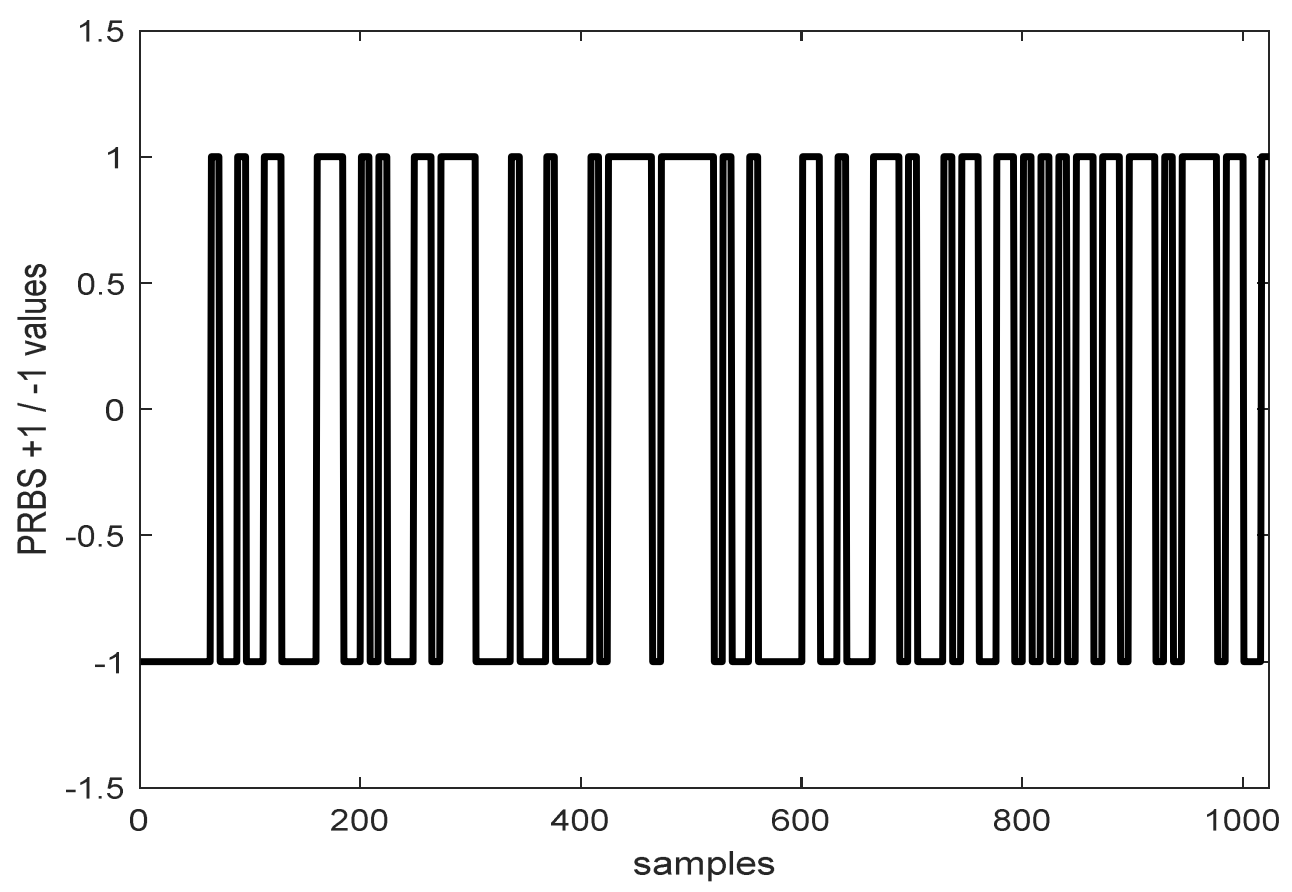

Figure 4.2: Initial generated PRBS signal

The transfer function model development is carried out by employing the 'tfest' function available in MATLAB. The input to this function is the generated data set and the output of this function is a transfer function in the $s$ domain. To obtain the mathematical model based on the transfer function technique, data sets that capture the dynamics of the process are generated from the dynamic hydrocracker model in MATLAB. For this purpose, a bi-level PRBS signal is used as input variables as shown on Figure 4.3 and the resulting data are collected for the output variables. The collected data can then be normalized depending on the different magnitudes of the input and the output variables. The obtained transfer function model in Matlab is further processed following the steps outlined in Figure 4.4 to generate discrete-time state-space matrices in the form of $\Phi, \Gamma$, C, D. Deviation variables for the inputs and outputs are calculated using Equation 4.23. 


$$
X_{\text {Dev }}=\frac{\left(X-X_{\text {sS }}\right)}{\left(X_{\max }-X_{S S}\right)} ; \quad X=T_{\text {in }}, T_{\text {out }}, w t, L H S V
$$

, where Dev indicates the deviated variables, ss indicates the steady-state value, max indicates the maximum value experienced in the data, $w t$ is the weight fraction of the product, and $T_{\text {in }}$ and $T_{\text {out }}$ are the inlet and outlet temperatures of the reactor, respectively.

The desired magnitudes of the bi-level signals are adjusted to ensure a certain boundedness in the outputs, due to the high nonlinearity of the hydrocracker unit. The other parameters discussed above for the PRBS signal development were determined by the MATLAB simulations from the dynamic non-isothermal hydrocracker developed earlier.

The signal magnitudes of each PRBS input were determined to ensure the signal would be constrained in the following operating conditions:

* Input temperature: $360-400{ }^{\circ} \mathrm{C}$

* LHSV: $0.3-0.7$

Figure 4.3 presents the designed signals with the necessary delays for experimental implementation already taken into consideration.

It should be noted that, the desired value of the input temperature into the hydrocracker reactor, $\mathrm{R} 2$, can be obtained by varying the temperature at the output of the furnace, F2, as depicted on Figure 1.1. 

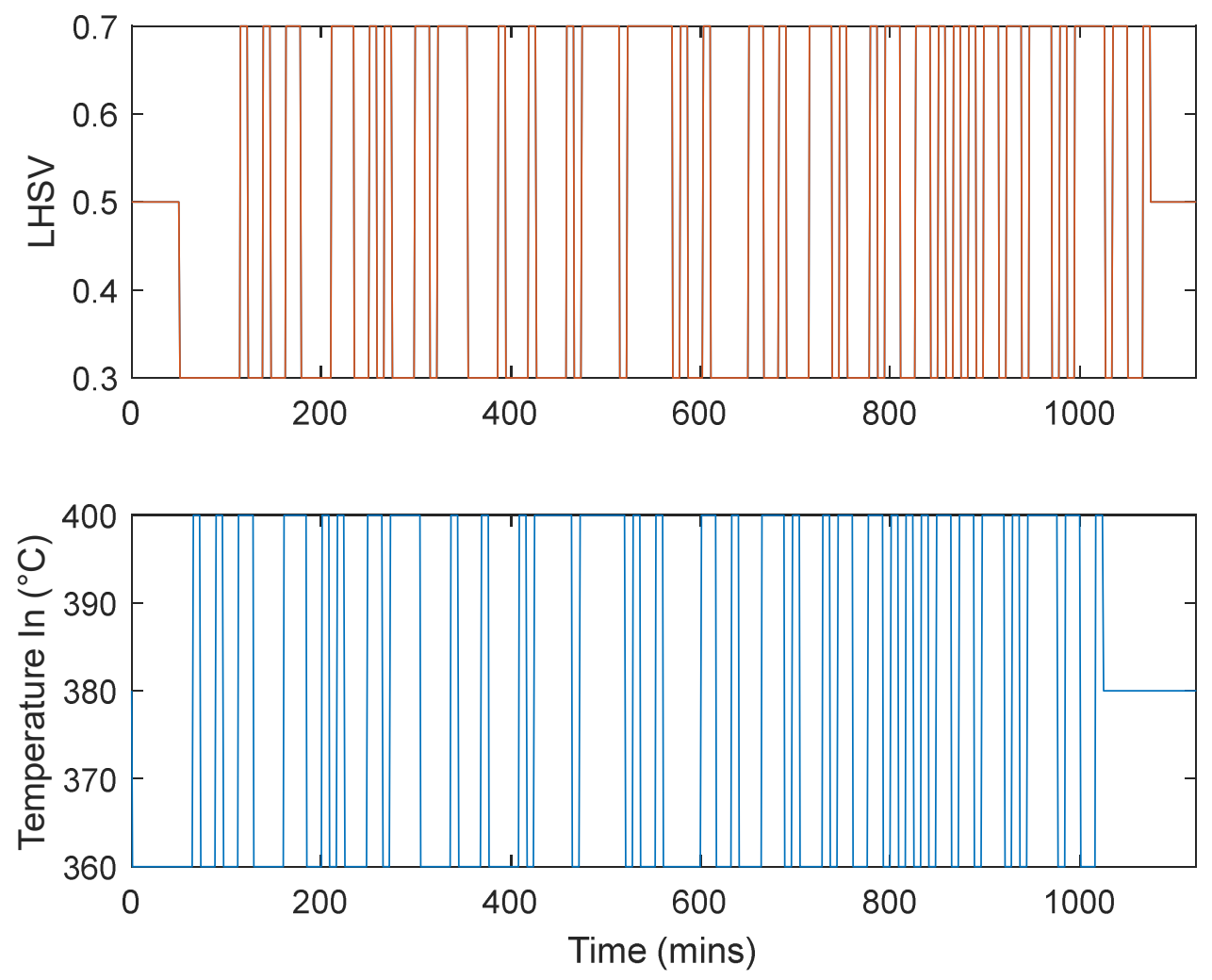

Figure 4.3: PRBS signals for system identification

The data collected from the PRBS inputs are fitted using the Matlab "tfest" function to estimate the transfer function of the system, as shown in Figures 4.5. The estimated transfer function is used to determine a state-space model for the system, which is then used for system control using the QDMC.

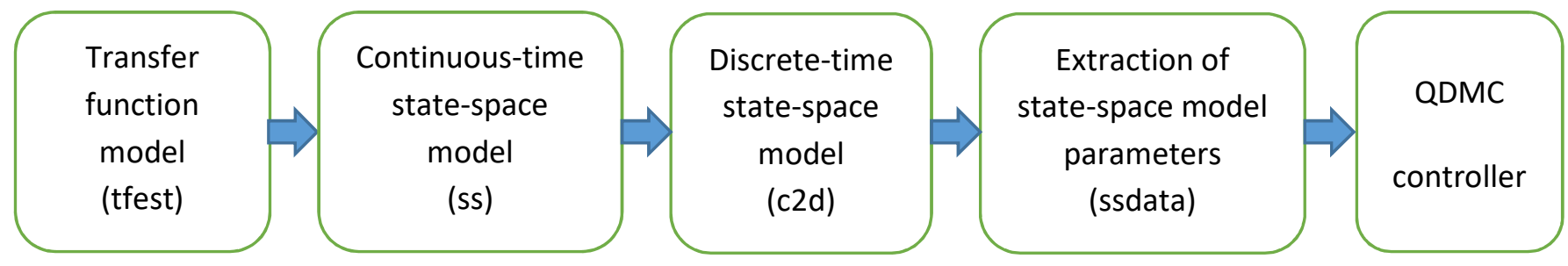

Figure 4.4: Summary of the steps for QDMC controller design 

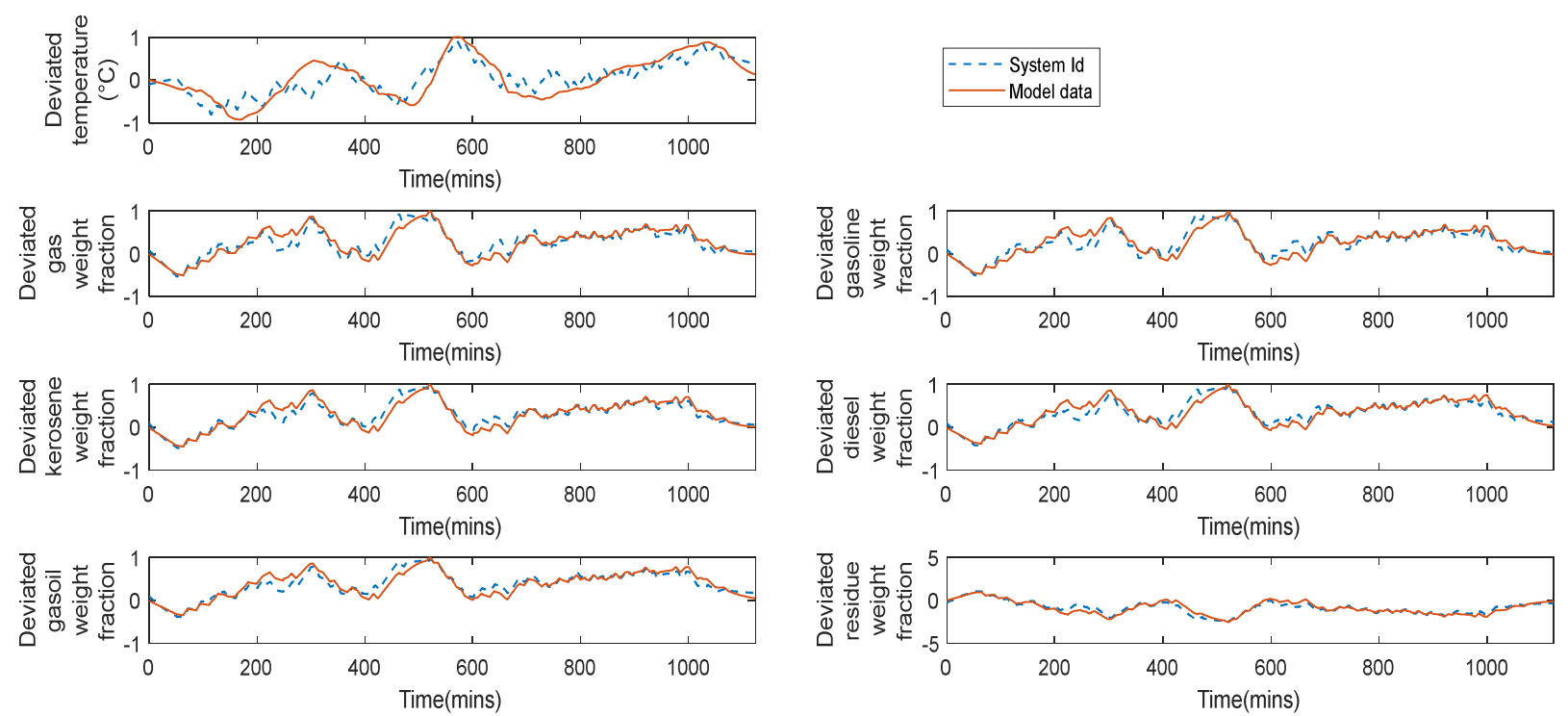

Figure 4.5: System identification

Figure 4.5 shows the fit obtained for the transfer function model; the model has a mean square error (MSE) of $0.0693{ }^{\circ} \mathrm{C}^{2}, 0.018,0.0171,0.012,0.0114,0.0117$ and 0.078 for output temperature, gas, gasoline, kerosene, diesel, gasoil, and residue weight fractions, respectively.

The identified discrete time state-space model is given by Equations 4.24 and 4.25.

$$
\begin{gathered}
x(i+1)=\Phi x(i)+\Gamma u(i) \\
y(i)=C x(i)+D u(i)
\end{gathered}
$$

, where

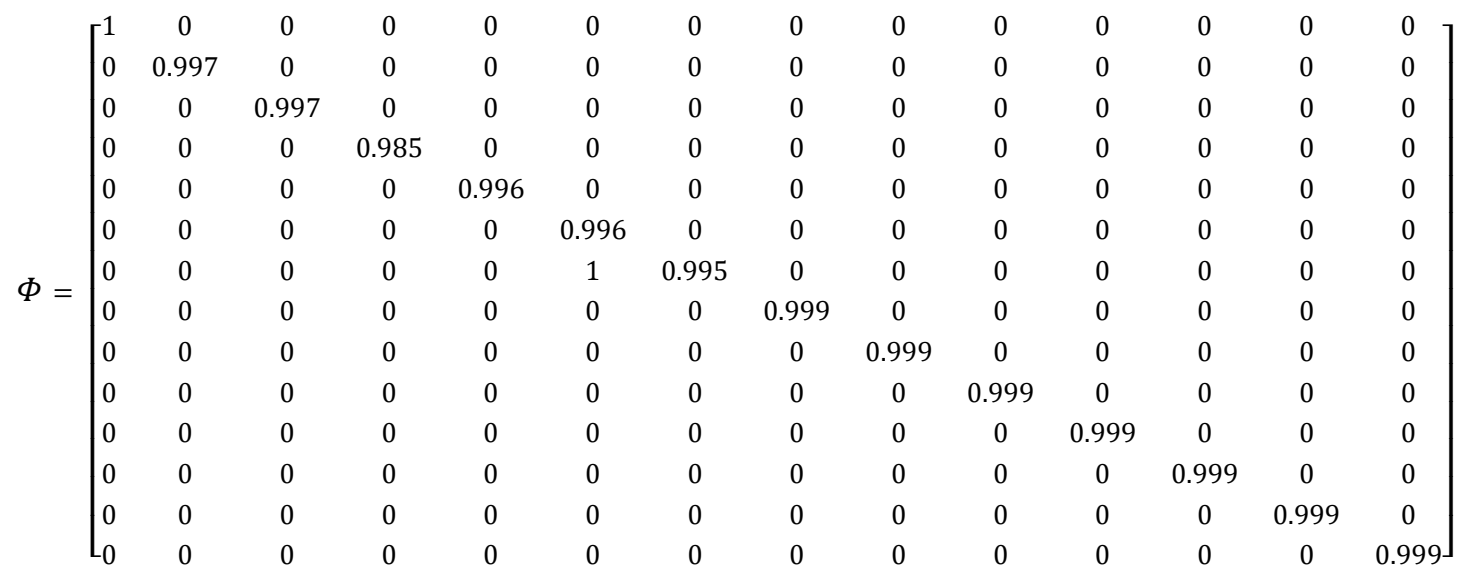




$$
\Gamma=\left[\begin{array}{cc}
0.0313 & 0 \\
0.125 & 0 \\
0.125 & 0 \\
0.125 & 0 \\
0.125 & 0 \\
0.125 & 0 \\
0.125 & 0 \\
0 & 0.125 \\
0 & 0.125 \\
0 & 0.125 \\
0 & 0.0625 \\
0 & 0.0625 \\
0 & 0.0625 \\
0 & 0.125
\end{array}\right] \quad D=\left[\begin{array}{cc}
-0.0203 & -0.0157 \\
0.0075 & 0.0203 \\
0.0004 & 0.0196 \\
0.0031 & 0.0183 \\
0.0049 & 0.0178 \\
-0.0007 & 0.0177 \\
-0.0029 & -0.0454
\end{array}\right]
$$

$C=\left[\begin{array}{cccccccccccccc}-0.029 & 0 & 0 & 0 & 0 & 0 & 0 & 0.151 & 0 & 0 & 0 & 0 & 0 & 0 \\ 0 & 0.98 & 0 & 0 & 0 & 0 & 0 & 0 & -0.11 & 0 & 0 & 0 & 0 & 0 \\ 0 & 0 & 0.097 & 0 & 0 & 0 & 0 & 0 & 0 & -0.106 & 0 & 0 & 0 & 0 \\ 0 & 0 & 0 & 0.11 & 0 & 0 & 0 & 0 & 0 & 0 & -0.09 & 0 & 0 & 0 \\ 0 & 0 & 0 & 0 & 0.099 & 0 & 0 & 0 & 0 & 0 & 0 & -0.093 & 0 & 0 \\ 0 & 0 & 0 & 0 & 0 & 0.91 & 0 & 0 & 0 & 0 & 0 & 0 & -0.096 & 0 \\ 0 & 0 & 0 & 0 & 0 & 0 & -0.13 & 0 & 0 & 0 & 0 & 0 & 0 & 0.118\end{array}\right]$

\subsection{SISO QDMC}

The state-space matrices obtained from the system identification are used in this section for the SISO control using the QDMC. Two cases are studied: servo control and disturbance rejection. The SISO QDMC was implemented with weight applied on the input control moves as $w=10^{4}$. The magnitudes of the lower and upper bounds of the input manipulated variable is constrained to a minimum and maximum of -3 and 3 , respectively. The changes in step moves $\left(\Delta u_{f}\right)$ are also constrained to a minimum and maximum of -0.5 and 0.5 , respectively. The SISO QDMC is designed with a model length of 2000, a prediction and control horizon of 1500 and 50 , respectively. It is also observed that the controller takes an average of 20 second to execute the control action. These results were obtained on Pentium 4 CPU, with a RAM of 4GB.

\subsubsection{Servo Control}

This section provides the results of the QDMC implemented for the control of the dynamic non-isothermal model. Results are shown in Figures 4.6 - 4.8, for gasoline, kerosene and diesel products, respectively. These results are generated by setting the volumetric flow rate constant, by considering inlet temperature as the manipulated variable, setting the outlet weight fraction of one 
of the products as the controlled variable, and by setting the reactor outlet temperature and weight fractions of the remaining products at the reactor outlet as free variables.
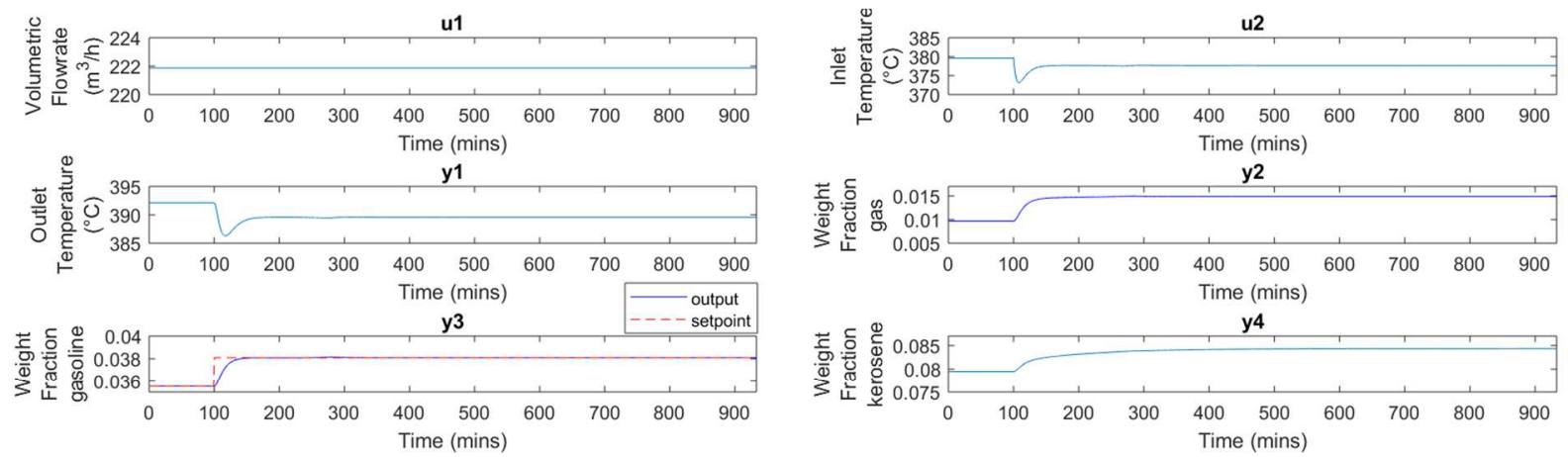

y5
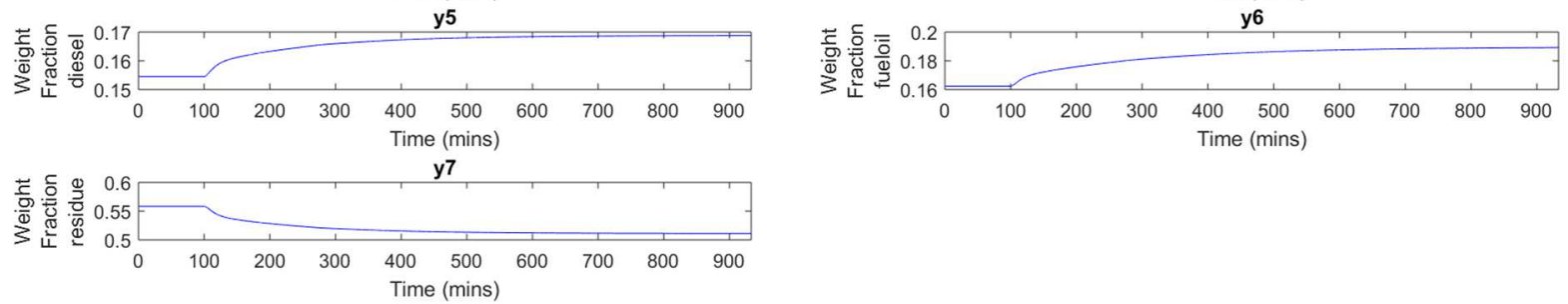

Figure 4.6: Input and output response of QDMC for gasoline weight fraction control
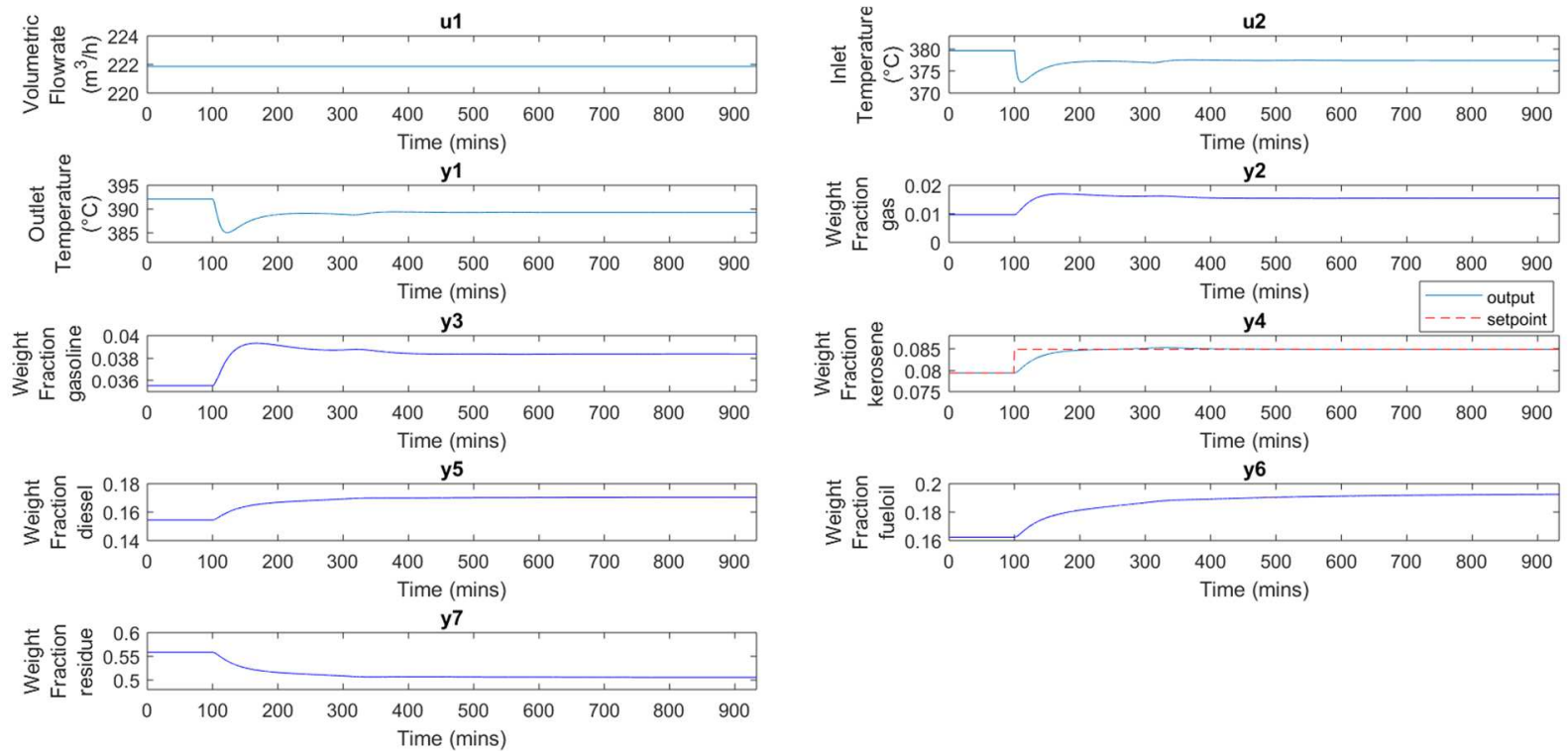

Figure 4.7: Input and output response of QDMC for kerosene weight fraction control 

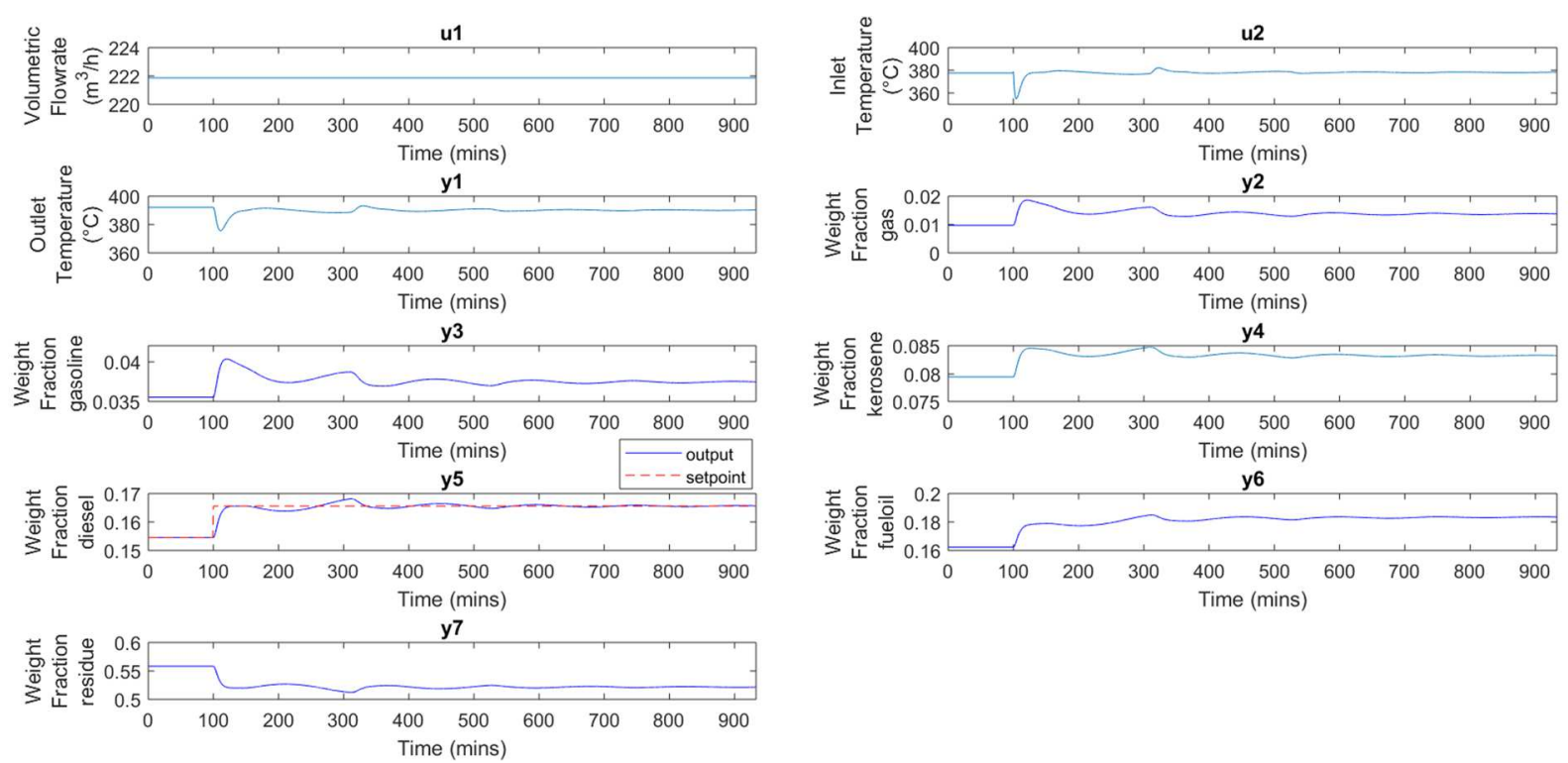

Figure 4.8: Input and output response of QDMC for diesel weight fraction control

It is observed that the QDMC response is satisfactory for servo control. The desired setpoint for each of the controlled variables is achieved without violating operational constraints. Figure 4.6 depicts a drop in the residue products when the gasoline product is stepped up, which would be expected. There is a little decrease in both the inlet and outlet temperatures of the reactor. Figures 4.7 and 4.8, which are the step up of kerosene and diesel weight fractions, respectively, depict similar results as that obtained in Figure 4.6. It can further be observed from figure 4.8 that, there is not much change to the inlet and outlet temperatures.

\subsubsection{Disturbance rejection}

The volumetric flow rate of the feed to the hydrocracker is considered as the disturbance, while the inlet temperature is the manipulated variable. A series of ramp and step tests are implemented to evaluate the disturbance rejection characteristics of the controller. Figures 4.94.11 show how the QDMC rejects the disturbance when the controlled variable is gasoline weight fraction, kerosene weight fraction or diesel weight fraction at the outlet, respectively. 

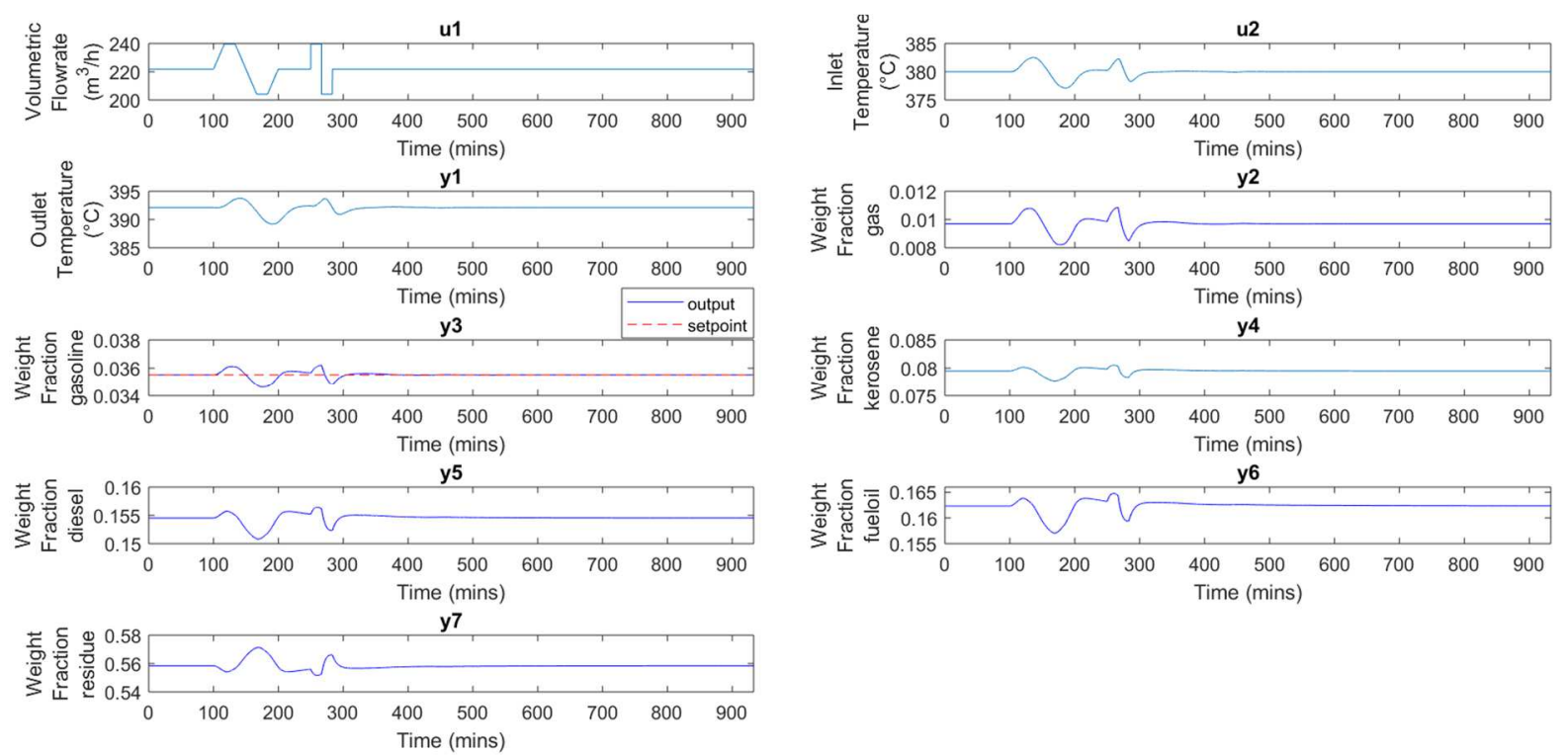

Figure 4.9: Disturbance rejection characteristics of QDMC for gasoline control
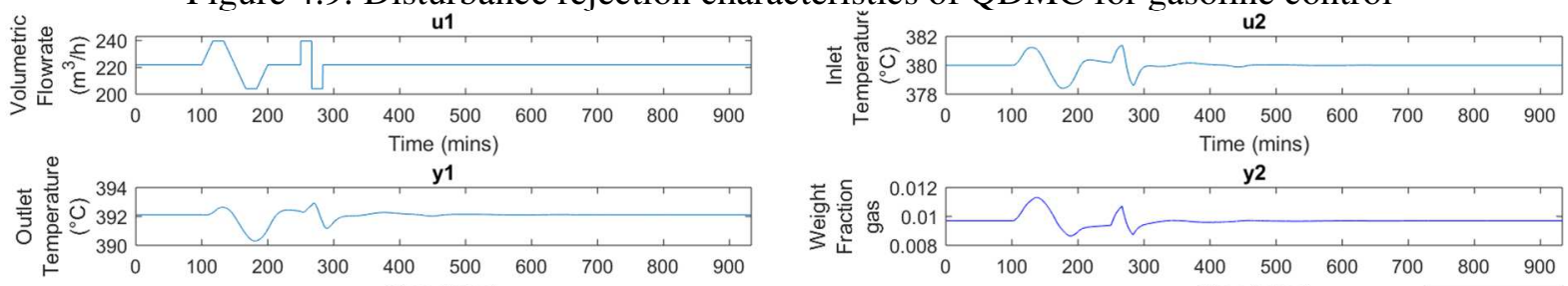

y3

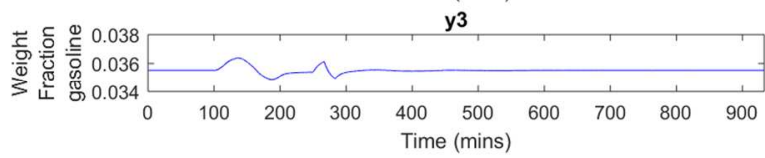

y5
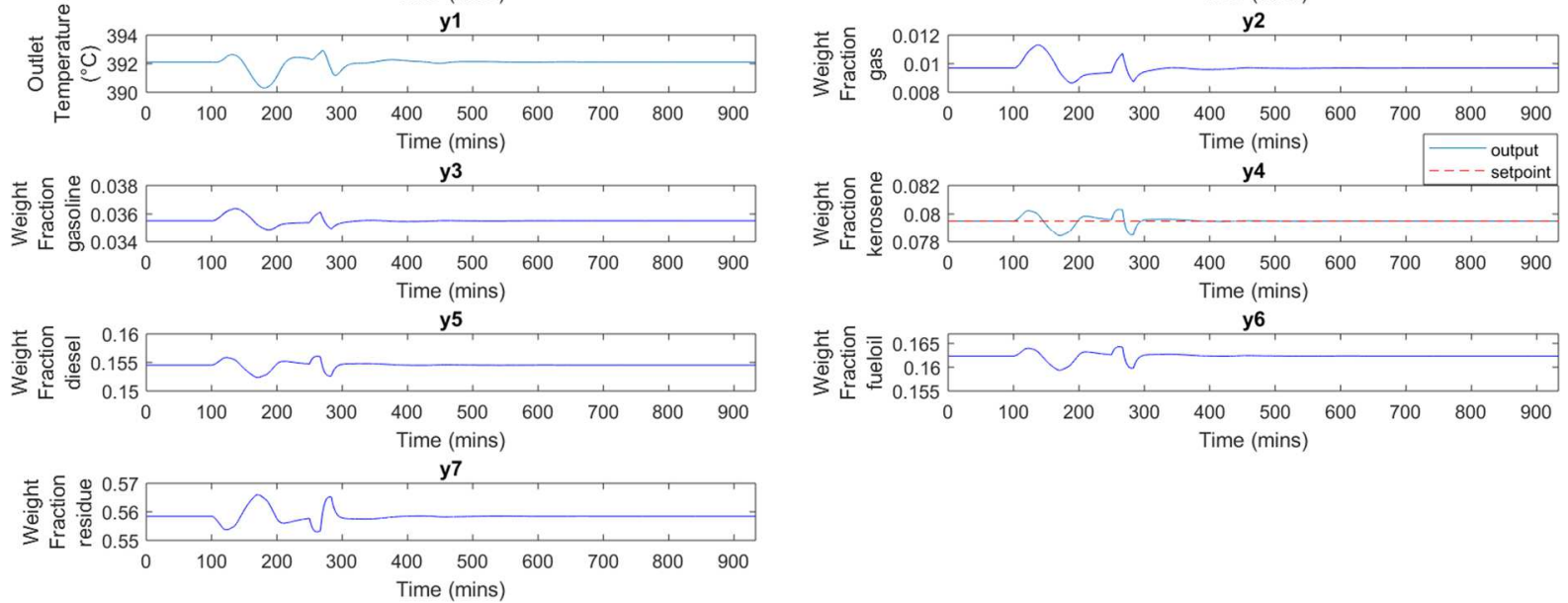

Figure 4.10: Disturbance rejection characteristics of QDMC for kerosene control 

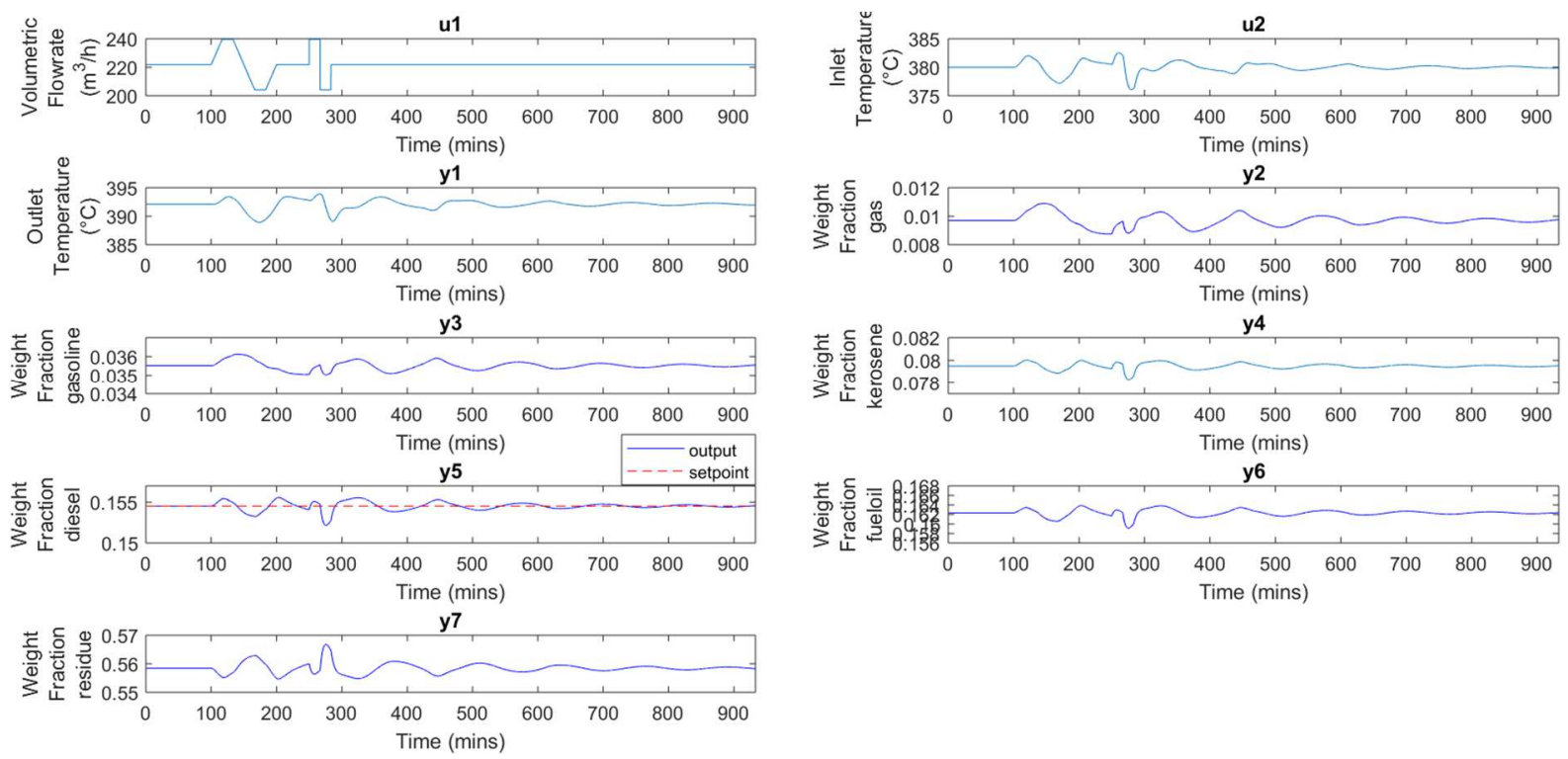

Figure 4.11: Disturbance rejection characteristics of QDMC for diesel control

It is observed that the QDMC responds satisfactorily for disturbance rejection. Figure 4.9 shows the disturbance rejection characteristics when the gasoline weight fraction is the controlled variable. There is very little variation in the weight fraction of the different products as a result of the disturbance. The temperature trend actually follows the trend of the disturbance, but a delay is noticed in the output temperature, which would be expected due to the transport delay. The same characteristics can be observed for the responses shown in Figures 4.10-11, for kerosene and diesel weight fraction control, respectively.

\subsection{MIMO QDMC}

For many refiners due to product marketing constraints, it may be desired to obtain certain desired weight fraction of more than one product even at the cost of plant throughput, if needed. In this section, this scenario is evaluated by designing the MIMO controller. The MIMO QDMC is developed with volumetric flowrate $\left(u_{1}\right)$ and input temperature $\left(u_{2}\right)$ as manipulated variables, and the weight fractions of two of the output products being the controlled variables, while the output temperature and the remaining product are free variables. The MIMO QDMC was implemented with weight applied on the input control moves as $w_{1}=10^{2}$ and $w_{2}=10^{4}$. The 
magnitudes of the upper and lower bounds of the input manipulated variables are constrained to a minimum and maximum of -0.5 and 0.5 , respectively for $u_{1}$ and -3 and 3 , respectively for $u_{2}$. The changes in step moves $\left(\Delta u_{f}\right)$ are also constrained to a minimum and maximum of -0.5 and 0.5 , respectively. The MIMO QDMC is designed with a model length of 2500, a prediction and control horizon of 1500 and 50, respectively.

Figures 4.12 shows the results when both gasoline and kerosene weight fractions are controlled simultaneously.
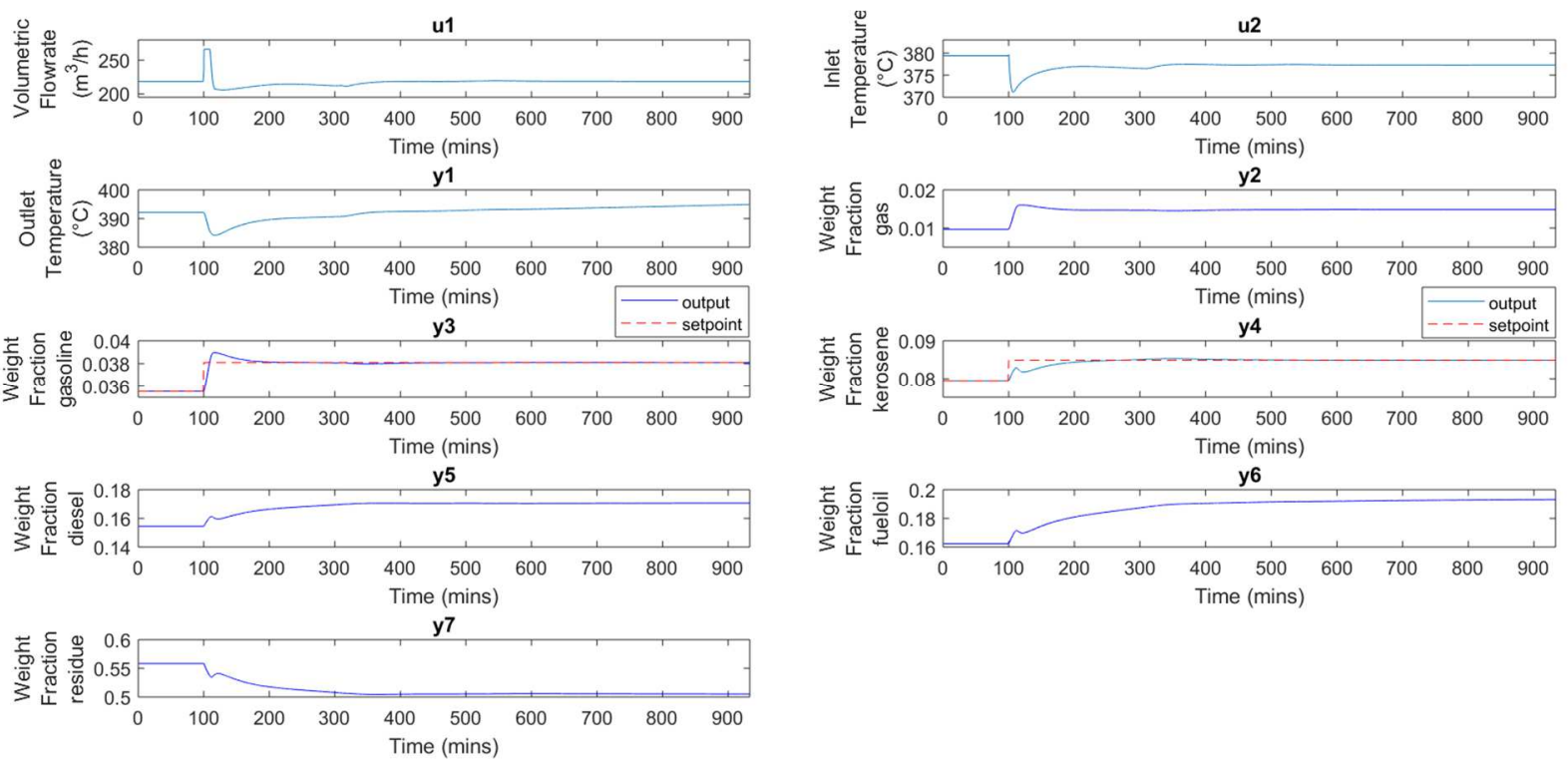

Figure 4.12: Input and output response of MIMO QDMC for gasoline and kerosene weight control

The controller can satisfy the desired weight fractions of two products at the same time without violating the input constraints. It is interesting to note that there is an initial increase in the flowrate into the reactor for the fast response, but the flowrate is eventually decreased in comparison to the steady state value. The inlet temperatures of the reactor also decrease. 


\subsection{Conclusion}

SISO and MIMO control of a hydrocracker reactor is studied in this work. A PRBS sequence was used as inputs for the identification of the dynamic non-isothermal hydrocracker model. The reduced model is implemented in the SISO and MIMO QDMC controllers. The performance of the SISO QDMC for both disturbance rejection and servo control are found to be satisfactory. Servo and disturbance rejection characteristics of the MIMO QDMC controller are also found to be satisfactory. It was observed that the MIMO controller could satisfy the change in the desired weight fraction of two products at a time without violating any constraints and without sacrificing the plant throughput. 


\section{CHAPTER 5: FINAL REMARKS AND RECOMMENDATIONS}

This research work explores the development of a non-isothermal hydrocracker reactor using the continuous kinetic lumping approach. Parameter estimation and computational time is greatly reduced by leveraging Aspen Plus to divide the petroleum into different fractions. The final model is found to provide satisfactory estimates of the temperature and weight fractions of products from this reactor.

The PRBS sequence system identification strategy is utilized to develop a reduced model for the dynamic non-isothermal hydrocracker reactor. The reduced model is a linearized statespace matrix that is implemented for the SISO and MIMO QDMC controls. Performance of the QDMC controllers for both SISO control and MIMO control are found to be satisfactory.

Development of the plant-wide control considering the entire hydrocracker plant will be a nice contribution in the future. This control system can be designed to maximize the plant profit while maintaining product qualities. Linear and nonlinear MPC can be investigated for developing such plant-wide control system.

The continuous kinetic lumping technique can be employed to design a hydrodesulfurization reactor, which is used upstream to the hydrocracker reactor. The design of such a unit will be very beneficial for the industry for maintaining product quality while maximizing the profit. 


\section{APPENDIX A: COMPOSITION OF FEED AND HYDROCRACKED PRODUCTS WITH}

A FBP OF $700{ }^{\circ} \mathrm{C}$

\begin{tabular}{|c|c|c|c|c|c|c|}
\hline & \multicolumn{3}{|c|}{ FEED } & \multicolumn{3}{|c|}{ PRODUCT } \\
\hline & $\begin{array}{l}\text { Temperature } \\
\left({ }^{\circ} \mathbf{C}\right)\end{array}$ & $\begin{array}{l}\text { Dimensionless } \\
\text { temperature }(\Theta)\end{array}$ & $\begin{array}{c}\text { cumulative } \\
\text { weight fractions }\end{array}$ & $\begin{array}{c}\text { Temperature } \\
\left({ }^{\circ} \mathbf{C}\right)\end{array}$ & $\begin{array}{l}\text { Dimensionless } \\
\text { temperature }(\Theta)\end{array}$ & $\begin{array}{c}\text { cumulative } \\
\text { weight fractions }\end{array}$ \\
\hline \multirow{5}{*}{ 岀 } & $\mathrm{CH} 4$ & 0 & 0 & -161.55 & 0 & 0.0012 \\
\hline & $\mathrm{C} 2 \mathrm{H} 6$ & 0.0847 & 0 & -88.55 & 0.0846 & 0.0026 \\
\hline & $\mathrm{H} 2 \mathrm{~S}$ & 0.1183 & 0 & -59.65 & 0.1182 & 0.0191 \\
\hline & $\mathrm{C} 3 \mathrm{H} 8$ & 0.1387 & 0 & -42.05 & 0.1386 & 0.0218 \\
\hline & $\mathrm{C} 4 \mathrm{H} 10$ & 0.187 & 0 & -0.45 & 0.1869 & 0.0222 \\
\hline \multirow{16}{*}{$\begin{array}{l}\text { 号 } \\
\text { ơ }\end{array}$} & 30.21 & 0.2226 & 0 & 56.48 & 0.253 & 0.0302 \\
\hline & 136.4 & 0.3458 & 0.05 & 127.44 & 0.3354 & 0.0711 \\
\hline & 187.8 & 0.4055 & 0.1 & 175.17 & 0.3908 & 0.12 \\
\hline & 227.1 & 0.4511 & 0.15 & 205.66 & 0.4262 & 0.1689 \\
\hline & 261.1 & 0.4906 & 0.2 & 231.37 & 0.456 & 0.2178 \\
\hline & 292.9 & 0.5275 & 0.25 & 255.37 & 0.4839 & 0.2667 \\
\hline & 325.87 & 0.5657 & 0.3 & 281.94 & 0.5147 & 0.3156 \\
\hline & 360.54 & 0.606 & 0.35 & 308.69 & 0.5458 & 0.3644 \\
\hline & 394.92 & 0.6459 & 0.4 & 332.86 & 0.5738 & 0.4133 \\
\hline & 428.12 & 0.6844 & 0.45 & 358.56 & 0.6037 & 0.4622 \\
\hline & 461.69 & 0.7234 & 0.5 & 386.02 & 0.6356 & 0.5111 \\
\hline & 497.08 & 0.7645 & 0.55 & 412.97 & 0.6668 & 0.56 \\
\hline & 533.84 & 0.8071 & 0.6 & 438.48 & 0.6964 & 0.6089 \\
\hline & - & - & - & 468.37 & 0.7311 & 0.6578 \\
\hline & - & - & - & 500.05 & 0.7679 & 0.7067 \\
\hline & - & - & - & 532.88 & 0.806 & 0.7556 \\
\hline
\end{tabular}




\section{APPENDIX B : PUBLICATIONS}

\section{JOURNAL PAPER}

1) Ayafor, C., Bhattacharyya, D, "Dynamic Modeling, Parameter Estimation, and QDMC Design for a Hydrocracker", to be Submitted to Industrial and Engineering Chemistry Research, 2018. 


\section{REFERENCES}

[1] J. Ancheyta, S. Sánchez, and M. A. Rodríguez, "Kinetic modeling of hydrocracking of heavy oil fractions: A review," Catal. Today, vol. 109, no. 1, pp. 76-92, Nov. 2005.

[2] S. A. Qader and G. R. Hill, "Hydrocracking of Gas Oil," Ind. Eng. Chem. Process Des. Dev., vol. 8, no. 1, pp. 98-105, Jan. 1969.

[3] M. A. Callejas and M. T. Martínez, "Hydrocracking of a Maya Residue. Kinetics and Product Yield Distributions," Ind. Eng. Chem. Res., vol. 38, no. 9, pp. 3285-3289, Sep. 1999.

[4] B. E. Stangeland, "A Kinetic Model for the Prediction of Hydrocracker Yields," Ind. Eng. Chem. Process Des. Dev., vol. 13, no. 1, pp. 71-76, Jan. 1974.

[5] C. S. Laxminarasimhan, R. P. Verma, and P. A. Ramachandran, "Continuous lumping model for simulation of hydrocracking," AlChE J., vol. 42, no. 9, pp. 2645-2653, Sep. 1996.

[6] U. Ray Chaudhuri, U. R. Chaudhuri, S. Datta, and S. K. Sanyal, "MILD HYDROCRACKING - A STATE OF THE ART," Fuel Sci. Technol. Int., vol. 13, no. 9, pp. 1199-1213, Sep. 1995.

[7] I. Elizalde, F. S. Mederos, V. Y. Mena-Cervantes, R. Hernández-Altamirano, and J. A. D. Muñoz, "Dynamic modeling of adiabatic reactor for hydrocracking of VGO by using of the continuous lumping approach," Fuel Process. Technol., vol. 152, pp. 200-206, Nov. 2016.

[8] H. Sildir, Y. Arkun, B. Cakal, D. Gokce, and E. Kuzu, "A dynamic non-isothermal model for a hydrocracking reactor: Model development by the method of continuous lumping and application to an industrial unit," J. Process Control, vol. 22, no. 10, pp. 1956-1965, Dec. 2012.

[9] E. Aydın et al., "Dynamic modeling of an industrial diesel hydroprocessing plant by the method of continuous lumping," Comput. Chem. Eng., vol. 82, pp. 44-54, Nov. 2015.

[10] I. Elizalde and J. Ancheyta, "On the detailed solution and application of the continuous kinetic lumping modeling to hydrocracking of heavy oils," Fuel, vol. 90, no. 12, pp. 3542-3550, Dec. 2011.

[11] S. J. Qin and T. A. Badgwell, "An Overview Of Industrial Model Predictive Control Technology," 1997, pp. 232-256.

[12] C. R. Cutler and B. L. Ramaker, "Dynamic Matrix Control_A Computer Control Algorithm | Matrix (Mathematics) | Errors And Residuals," Scribd. [Online]. Available: https://www.scribd.com/document/252143441/Dynamic-Matrix-Control-A-Computer-ControlAlgorithm. [Accessed: 27-Mar-2018].

[13] C. E. Garcia and M. Morari, "Internal model control. A unifying review and some new results," Ind. Eng. Chem. Process Des. Dev., vol. 21, no. 2, pp. 308-323, Apr. 1982.

[14] D. W. Clarke, C. Mohtadi, and P. S. Tuffs, "Generalized predictive control-Part I. The basic algorithm," Automatica, vol. 23, no. 2, pp. 137-148, Mar. 1987.

[15] D. W. Clarke, C. Mohtadi, and P. S. Tuffs, "Generalized Predictive Control-Part II Extensions and interpretations," Automatica, vol. 23, no. 2, pp. 149-160, Mar. 1987.

[16] C. R. Cutler and R. B. Hawkins, "Constrained Multivariable Control of a Hydrocracker Reactor," in 1987 American Control Conference, 1987, pp. 1014-1020.

[17] J. B. Rawlings and K. R. Muske, "The stability of constrained receding horizon control," IEEE Trans. Autom. Control, vol. 38, no. 10, pp. 1512-1516, Oct. 1993.

[18] D. Q. Mayne, J. B. Rawlings, C. V. Rao, and P. O. M. Scokaert, "Constrained model predictive control: Stability and optimality," p. 26, 2000.

[19] S. J. Qin and T. A. Badgwell, "A survey of industrial model predictive control technology," Control Eng. Pract., vol. 11, no. 7, pp. 733-764, Jul. 2003.

[20] S. V. Gaikwad and D. E. Rivera, "Control-Relevant Input Signal Design for Multivariable System Identification: Application to High-Purity Distillation," IFAC Proc. Vol., vol. 29, no. 1, pp. 6143-6148, Jun. 1996. 
[21] S. Deshpande and D. E. Rivera, "Optimal input signal design for data-centric estimation methods," in 2013 American Control Conference, 2013, pp. 3924-3929.

[22] Y. Zhu, "Multivariable process identification for mpc: the asymptotic method and its applications," $J$. Process Control, vol. 8, no. 2, pp. 101-115, Apr. 1998.

[23] U.-C. Moon and K. Y. Lee, "Step-Response Model Development for Dynamic Matrix Control of a Drum-Type Boiler-Turbine System," IEEE Trans. Energy Convers., vol. 24, no. 2, pp. 423-430, Jun. 2009.

[24] I. Elizalde, F. Trejo, J. A. D. Muñoz, P. Torres, and J. Ancheyta, "Dynamic modeling and simulation of a bench-scale reactor for the hydrocracking of heavy oil by using the continuous kinetic lumping approach," React. Kinet. Mech. Catal., vol. 118, no. 1, pp. 299-311, Jun. 2016.

[25] S. Mohanty, D. N. Saraf, and D. Kunzru, "Modeling of a hydrocracking reactor," Fuel Process. Technol., vol. 29, no. 1, pp. 1-17, Nov. 1991.

[26] N. Dadgostar and J. M. Shaw, "A predictive correlation for the constant-pressure specific heat capacity of pure and ill-defined liquid hydrocarbons," Fluid Phase Equilibria, vol. 313, no. Supplement C, pp. 211-226, Jan. 2012.

[27] B. W. Bequette, Process control: modeling, design, and simulation, 1 online resource (xxix, 769 pages): illustrations. vols. Upper Saddle River, N.J.: Prentice Hall PTR, 2003.

[28] L. Bitjoka, M. Ndje, A. T. Boum, and J. Song-Manguelle, "Implementation of quadratic dynamic matrix control on arduino due ARM cortex-M3 microcontroller board," J. Eng. Technol., vol. 6, no. 2, p. 15, 2017. 